\title{
Shallow crustal composition of Mercury as revealed by spectral properties and geological units of two impact craters
}

\author{
Piero D’Incecco $^{\text {a,*, }}{ }^{\text {, Jörn Helbert }}{ }^{\mathrm{a}}$, Mario D’Amore ${ }^{\mathrm{a}}$, Alessandro Maturilli ${ }^{\mathrm{a}}$, James W. Head ${ }^{\mathrm{b}}$, \\ Rachel L. Klima ${ }^{\mathrm{c}}$, Noam R. Izenberg ${ }^{\mathrm{c}}$, William E. McClintock ${ }^{\mathrm{d}}$, Harald Hiesinger ${ }^{\mathrm{e}}$, \\ Sabrina Ferrari ${ }^{\mathrm{a}}$ \\ a Institute of Planetary Research, German Aerospace Center, Rutherfordstrasse 2, D-12489 Berlin, Germany \\ ${ }^{\mathrm{b}}$ Department of Geological Sciences, Brown University, Providence, RI 02912, USA \\ c The Johns Hopkins University Applied Physics Laboratory, Laurel, MD 20723, USA \\ d Laboratory for Atmospheric and Space Physics, University of Colorado, Boulder, CO 80303, USA \\ e Westfälische Wilhelms-Universität Münster, Institut für Planetologie, Wilhelm-Klemm Str. 10, D-48149 Münster, Germany
}

\section{A R T I C L E I N F O}

\section{Article history:}

Received 5 March 2015

Received in revised form

9 October 2015

Accepted 12 October 2015

Available online 24 October 2015

\section{Keywords:}

Mercury

MESSENGER

MASCS

MDIS

Impact craters

Stratigraphy

\begin{abstract}
A B S T R A C T
We have performed a combined geological and spectral analysis of two impact craters on Mercury: the $15 \mathrm{~km}$ diameter Waters crater $\left(106^{\circ} \mathrm{W} ; 9^{\circ} \mathrm{S}\right)$ and the $62.3 \mathrm{~km}$ diameter Kuiper $\operatorname{crater}\left(30^{\circ} \mathrm{W} ; 1^{\circ} \mathrm{S}\right)$. Using the Mercury Dual Imaging System (MDIS) Narrow Angle Camera (NAC) dataset we defined and mapped several units for each crater and for an external reference area far from any impact related deposits. For each of these units we extracted all spectra from the MESSENGER Atmosphere and Surface Composition Spectrometer (MASCS) Visible-InfraRed Spectrograph (VIRS) applying a first order photometric correction. For all the mapped units, we analyzed the spectral slope in two wavelength ranges, 350-450 nm and $450-650 \mathrm{~nm}$, and the absolute reflectance in the $700-750 \mathrm{~nm}$ range. Normalized spectra of Waters crater display a generally bluer spectral slope than the external reference area over both wavelength windows. Normalized spectra of Kuiper crater generally display a redder slope than the external reference area in the 350-450 nm window, while they display a bluer slope than the external reference area in the 450-650 nm wavelength range. The combined use of geological and spectral analyses enables reconstruction of the local scale stratigraphy beneath the two craters, providing insight into the properties of the shallower crust of Mercury. Kuiper crater, being $\sim 4$ times larger than Waters crater, exposes deeper layers with distinctive composition, while the result for Waters crater might indicate substantial compositional homogeneity with the surrounding intercrater plains, though we cannot exclude the occurrence of horizontal compositional heterogeneities in the shallow sub-surface.
\end{abstract}

(c) 2015 Elsevier Ltd. All rights reserved.

\section{Introduction}

The Mariner 10 mission unveiled the general morphology of Mercury, allowing a first geologic mapping of its surface. The MErcury Surface, Space ENvironment, GEochemistry and Ranging (MESSENGER) mission went farther, providing more detailed information through the combination of morphology and spectral analysis. The goal of this work is to reconstruct the local stratigraphy beneath the two craters using a geologically supervised spectral analysis. This technique, combining spectral analysis and geologic interpretation, can serve as a tool for identifying vertical and horizontal heterogeneities in the crust of Mercury, allowing

\footnotetext{
* Corresponding author.

E-mail address: piero.dincecco@dlr.de (P. D'Incecco).
}

the reconstruction of the local scale stratigraphy beneath the surface indeed. Impact craters can open a window into the shallow crust of Mercury, as they excavate materials from depth. The spectral properties of these materials can reveal vertical or horizontal compositional heterogeneities in the shallow crust, although these compositional differences may be obscured by several factors, including space weathering, impact metamorphism, and differences in grain size. This study provides a local scale characterization of two impact craters of Mercury, the $15 \mathrm{~km}$ diameter Waters crater $\left(106^{\circ} \mathrm{W} ; 9^{\circ} \mathrm{S}\right)$ and the $62.3 \mathrm{~km}$ diameter Kuiper crater $\left(30^{\circ} \mathrm{W} ; 11^{\circ} \mathrm{S}\right)$. We analyze and compare the spectral character of central peaks, internal deposits, impact melts and the fresh ejecta of both craters in function of the spectral properties of a region mapped as intercrater plains by Mariner 10 authors (i.e., De Hon et al. 1981; King and Scott, 1990). 


\section{Background}

\subsection{Geology of Mercury after the Mariner 10 mission}

The Mariner 10 spacecraft imaged approximately $40 \%$ of the surface of Mercury at a resolution more or less comparable to that of Earth-based observations of the Moon (Murray et al., 1974). In the mid-1970s, Mariner 10 science team members identified and divided Mercury's surface into morphologic and physiographic units such as intercrater plains, heavily cratered terrain and smooth plains (e.g., Trask and Guest, 1975; Gault et al. 1975; Trask, 1976; Strom, 1977; Kiefer and Murray, 1987; Spudis and Guest, 1988). Intercrater plains and heavily cratered terrain represent the oldest units of Mercury and their origins and chronostratigraphic relations have been studied by various authors (e.g., Strom, 1977; Trask and Guest, 1975; Trask and Strom, 1976).

In contrast to the intercrater plains, the smooth plains are characterized by a relatively low density of impact craters and by a smoother surface morphology. In accordance with the studies of Leake (1982), smooth plains have been interpreted by Mariner 10 geologic mappers to be stratigraphically younger than the intercrater plains (i.e., Schaber and McCauley, 1980; De Hon et al., 1981; Guest and Greeley, 1983; Grolier et al., 1660; King and Scott, 1990).

Intercrater plains, heavily cratered terrains and smooth plains were all plausibly emplaced during a very early phase of Mercury's surface history. The most recent chronostratigraphic periods, the Mansurian (which began between 3.0 and $3.5 \mathrm{Ga}$ ) and the Kuiperian $(1.0 \mathrm{Ga})$, are mainly characterized by the emplacement of impact craters and related material (Spudis and Guest, 1988).

\subsection{MESSENGER's studies}

Data acquired by the MESSENGER spacecraft have allowed key questions such as the origin of smooth plains to be revisited. The MDIS instrument has imaged $100 \%$ of Mercury's surface at a spatial resolution better than $200 \mathrm{~m} /$ pixel. Coupled with new spectra

Table 1

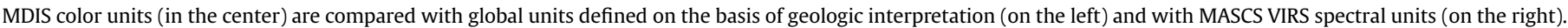
The correspondence is not total, but in some cases the overlap is possible.
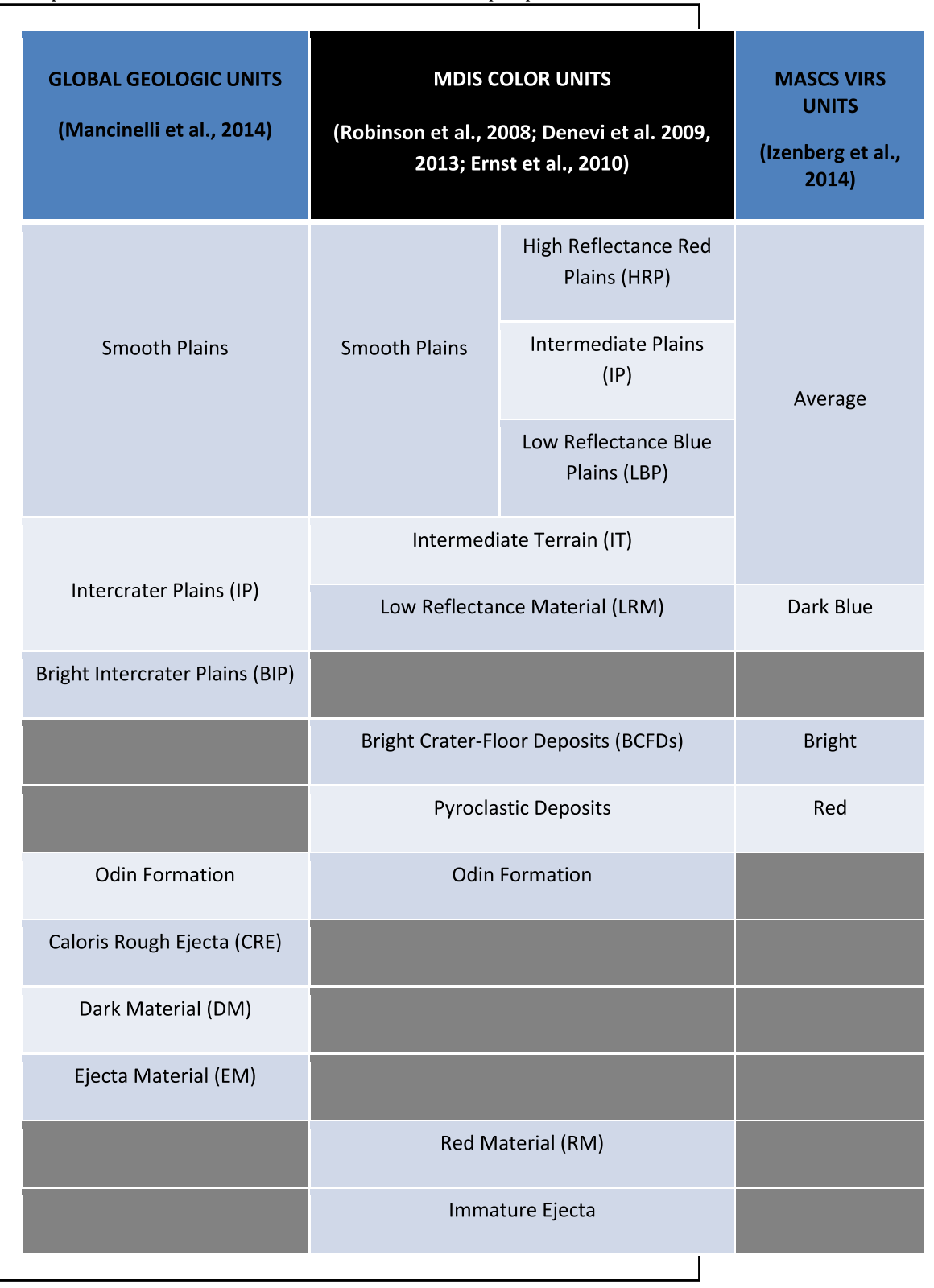
provided from both MDIS color data and the MASCS instrument, a more complete and detailed investigation of the crustal properties of Mercury is now possible. Robinson et al. (2008) and Denevi et al. (2009) analyzed the MDIS color images identifying a number of units on the basis of their spectral slope and relative reflectance (Table 1). Denevi et al. (2009) went further linking color units to the morphologic units previously defined using Mariner 10 data. On the basis of MESSENGER flyby data, Denevi et al. (2009) subdivided the former Mariner 10 units into additional units that take into considerations enhanced colors: the smooth plains, the intermediate terrain (IT) and the low-reflectance material (LRM) (Table 1). They also divided the smooth plains into three color subunits: the high-reflectance red plains (HRP), the intermediate plains (IP) and the low-reflectance blue plains (LBP) (Table 1). It is important to note that the intermediate plains as defined by Denevi et al. (2009) and intermediate plains as defined by Mariner 10 authors (e.g., Grolier et al., 1660; Spudis and Prosser, 1984; King and Scott, 1990) are not the same unit. To avoid any misunderstanding, Whitten et al. (2014) suggested remapping the whole unit, subdividing it into two different parts: intercrater plains and smooth plains.

Mancinelli et al. (2014) performed a comprehensive local scale geologic study of a portion of Raditladi quadrangle. Given the downscaling nature of their approach, these authors used already existing global units such as smooth plains and Odin Formation as defined by Denevi et al. (2013) and also defined a number of new global units. In particular, on the global scale, they defined: bright intercrater plains (BIP), the oldest mapped unit; intercrater plains (IP), including all LRM from Denevi et al. (2009) and "intermediate plains" from Trask and Dzurisin (1984); material ballistically ejected by the major impacts (EM); Caloris rough ejecta (CRE), covering deposits of Caloris rim and undulated deposits east of Caloris; dark material (DM), characterized by patches of low reflectance material located near or within impact craters (Table 1).

Building on the first findings of Robinson et al. (2008) and Denevi et al. (2009), other important color units have been classified by Ernst et al. (2010), including fresh (immature) crater ejecta, bright crater-floor deposits (BCFDs), and red material (RM) (Table 1). In most cases, fresh crater ejecta are characterized by brighter reflectance and slightly bluer spectral slopes, suggesting that the ejecta has been less affected by space weathering but that it is otherwise compositionally similar to the more mature surrounding deposits (Ernst et al., 2010). BCFDs, now referred to as hollows (Blewett et al., 2010), exhibit significantly higher reflectance and bluer slopes than their surroundings, possibly indicating compositional heterogeneities between the hollows and their surrounding deposits (Blewett et al. 2010). RM units (e.g., Robinson et al. 2008; Ernst et al. 2010) can be associated with central peaks and are characterized by relatively red spectra and high reflectance.

The wealth of orbital data from MESSENGER has allowed the origin of the smooth plains to be investigated in greater detail. Volcanic landforms such as shield volcanoes and volcanic vents had been initially identified within Caloris basin and smooth plains units occur also far away from large basins particularly in the northern hemisphere (e.g., Head et al., 2008, 2009a, 2009b, 2011; Denevi et al., 2013). On the other hand, Rothery et al. (2014) showed that Caloris basin vent floors are not situated at the summit of significant edifices, discounting the occurrence of shield volcanoes in Caloris basin. A subsequent study from Thomas et al. (2014) also showed similar lack of edifices outside of Caloris too. Weider et al. (2015) observations from MESSENGER's X-Ray Spectrometer (XRS) revealed that Caloris exhibits similar $\mathrm{Mg} / \mathrm{Si}$, $\mathrm{Ca} / \mathrm{Si}$, and $\mathrm{Al} / \mathrm{Si}$ values to the northern plains, suggesting that the deposits in Caloris as well as other HRP might share a magnesian alkali-basalt-like composition.

A recent study from Byrne et al. (2015) determined crater sizefrequency distributions for six smooth plains units on Mercury, showing that they are comparable to the values obtained by other authors for other smooth plains units (i.e., Denevi et al. 2013) and lower than the values obtained for intercrater plains (i.e., Whitten et al., 2014). Hence, this analysis provided further evidence that smooth plains are stratigraphically younger than intercrater plains.

Izenberg et al. (2014) used MASCS data to explore the global spectral properties of Mercury. To visualize the spectral diversity of the planet, they selected three spectral parameters: a) The reflectance at $575 \mathrm{~nm}$ wavelength (R575, red), b) the spectral slope at visible and infrared wavelengths, represented by the ratio of reflectance at $415 \mathrm{~nm}$ to that at $750 \mathrm{~nm}$ (VISr, green), c) the spectral slope at ultraviolet (UV) and visible wavelengths, represented by the ratio of reflectance at $310 \mathrm{~nm}$ to that at $390 \mathrm{~nm}(\mathrm{UVr}$, blue). Using these parameters, they divided Mercury's surface into four broad MASCS Visible and Infrared (VIRS) spectral units: average, dark blue, red and bright (Table 1 ). The average unit is characterized by reflectance within $25 \%$ of the mean planetary reflectance, an UVr value between 0.64 and 0.71 , and a VISr value between 0.5 and 0.6 (Izenberg et al., 2014). The plains as defined by MDIS color units (e.g., Robinson et al. 2008; Denevi et al. 2009, 2013) fall into this spectral VIRS unit (Izenberg et al. 2014). The dark blue VIRS spectral unit is characterized by spectra both darker than the planetary mean spectrum and less sloped or "bluer" (Izenberg et al., 2014). This unit includes all areas identified as LRM and some areas defined as LBP from the MDIS dataset (i.e., Robinson et al., 2008; Denevi et al., 2009; Denevi et al. 2013). The Red VIRS spectral unit is characterized by spectra that are both higher in reflectance and "redder" than the planetary mean spectrum, with a low UVr $(<0.66)$ and a low VISr $(<0.60)$ (Izenberg et al., 2014). This unit includes pyroclastic deposits defined on the basis of morphology and visible color as having formed through explosive volcanism (e.g., Head et al., 2008; Kerber et al., 2011; Goudge et al., 2014). The bright spectral unit covers a wide range of $\mathrm{UVr}(0.60-0.74)$, and it has a higher VISr value and is brighter than the highest reflectance values of the average unit (Izenberg et al., 2014). Hollows (Blewett et al., 2011, 2013; Helbert et al., 2013) have spectral parameters that fall within the bright VIRS spectral unit.

All the units defined above are displayed into Table 1, which compares the MDIS color units defined by Robinson et al. (2008), Denevi et al. (2009, 2013) and Ernst et al. (2010) with the global geologic units defined by Mancinelli et al. (2014) and the MASCS VIRS spectral units defined by Izenberg et al. (2014), respectively.

As a first-order classification, Helbert et al. (2013) have distinguished two mega-regions on the surface of Mercury: an Equatorial Region (ER) encompassing primarily middle latitudes, and a Polar Region (PR) that covers the two poles. Performing a comparative study between the smooth plains within Caloris basin and the smooth plains within Rembrandt basin, they noted that Caloris infill deposits belong mostly to the ER, with some scattered spot of PR, while Rembrandt's deposits are spectrally more similar to the PR. This is in contrast to earlier findings that suggested that the Caloris basin fill is spectrally similar to the northern plains (e.g., Denevi et al., 2013; Izenberg et al., 2014). The most recent XRS data show only partial similarities between the Caloris plains and the Northern plains, without confirming a complete compositional match (Weider et al., 2015).

\section{Regional context}

We selected two craters, both located near $10^{\circ}$ south of the equator of Mercury, for geological and spectral analyses (Fig. 1a). 

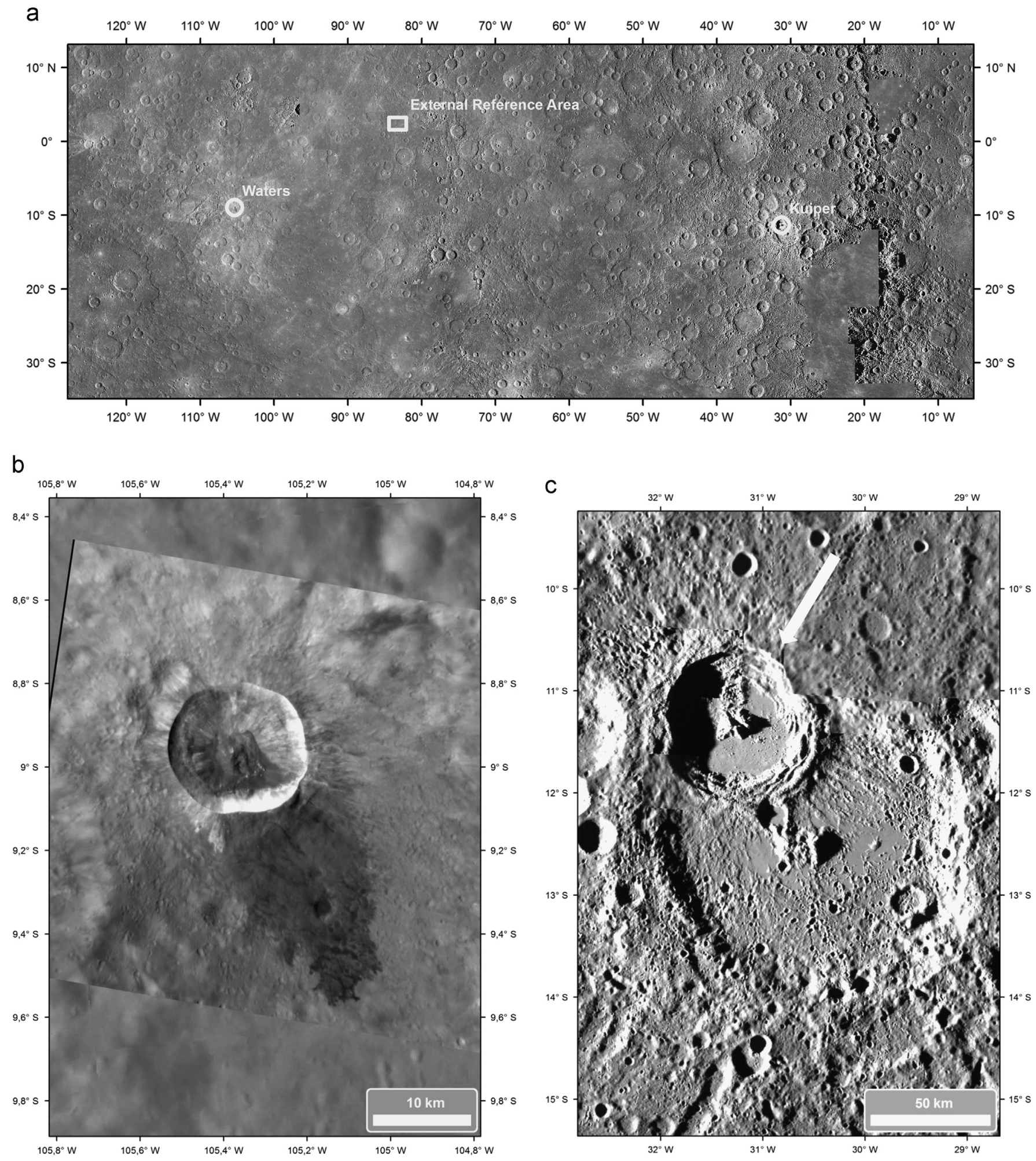

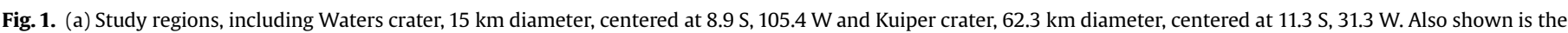

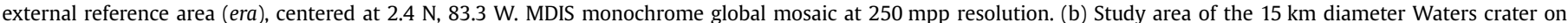

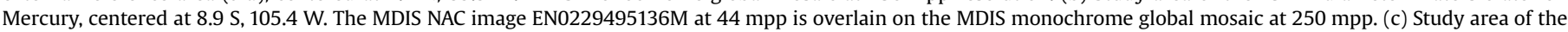

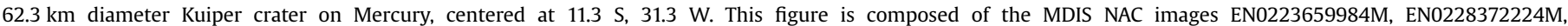
EN0228372226M, EN0228372268M, and EN0228372270M overlain on MDIS WAC image EW0223443634I.

This area includes part of two quadrangles: the $15 \mathrm{~km}$ diameter Waters crater $\left(106^{\circ} \mathrm{W}, 9^{\circ} \mathrm{S}\right.$; Fig. $\left.1 \mathrm{~b}\right)$ is located in the H07-Beethoven quadrangle (King and Scott, 1990), while the $62.3 \mathrm{~km}$ diameter
Kuiper crater $\left(30^{\circ} \mathrm{W}, 11^{\circ} \mathrm{S}\right.$; Fig. 1c) falls within the H06-Kuiper quadrangle (De Hon et al., 1981). Since the present study area has been already imaged by the Mariner 10 spacecraft, we build our 
a

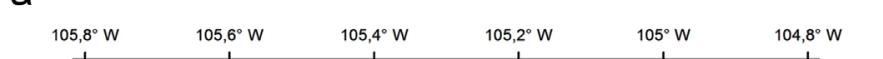

b

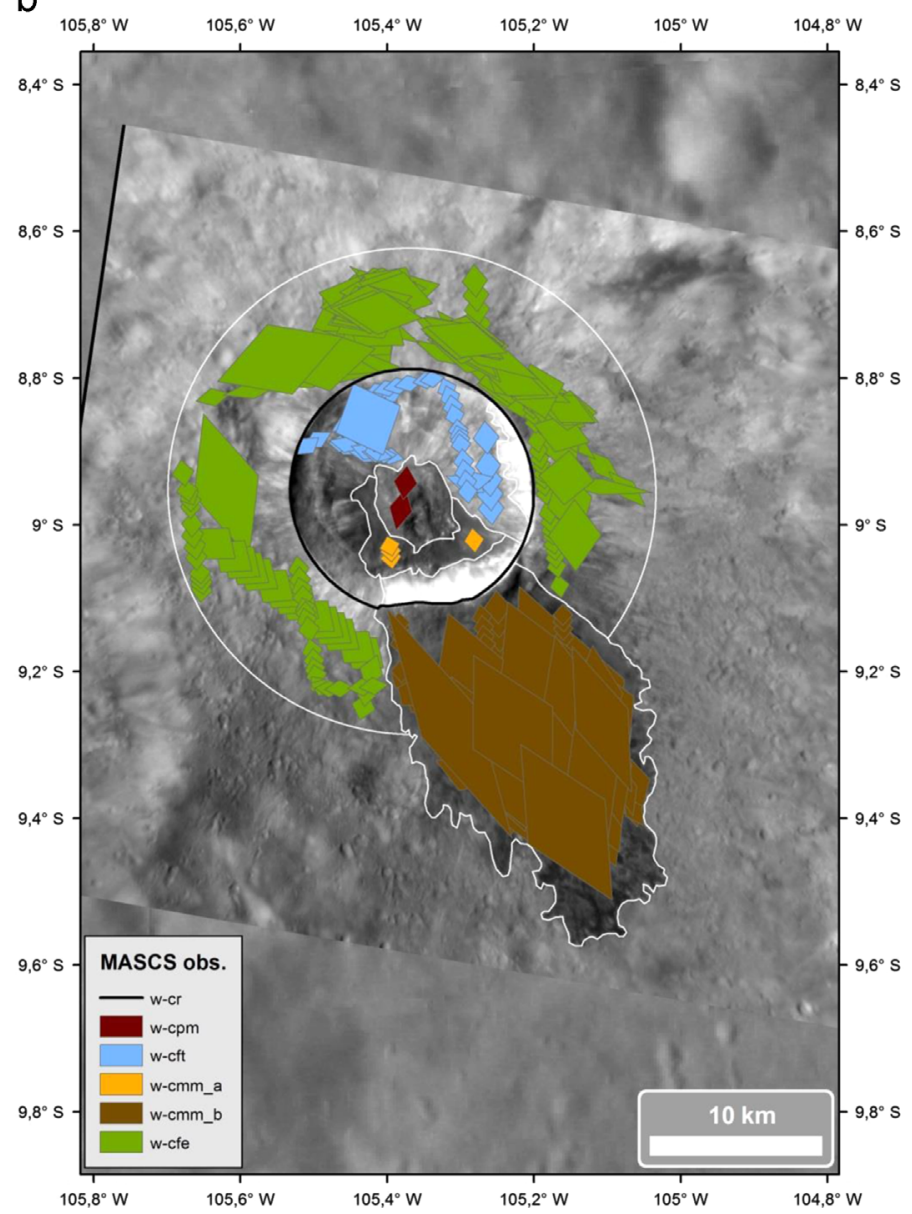

g. 2. (a) Waters crater $(8.9 \mathrm{~S}, 105.4 \mathrm{~W})$ geologic map. The mapped units are: Waters crater peak material $(w$-cpm), Waters crater floor and terraces $(w$-cft), Waters crater

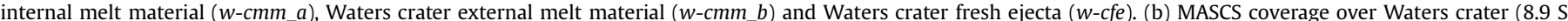

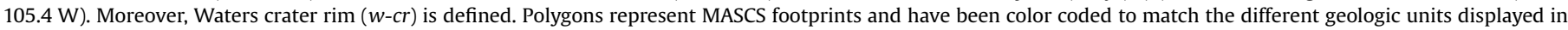
2a. Both panels use MDIS NAC image EN0229495136M at 44 mpp overlain on the MDIS monochrome global mosaic at 250 mpp as their background.

regional overview on the geologic maps created by De Hon et al. (1981) for the H06-Kuiper quadrangle and by King and Scott (1990) for the H07-Beethoven quadrangle.

Kuiper crater represents one of the youngest impact craters on Mercury (De Hon et al., 1981). For this reason, the youngest chronostratigraphic system of Mercury, the Kuiperian system (1.0 Ga ago), is named after this crater (e.g., Spudis and Guest, 1988). Waters craters is also very young, so that both Kuiper crater and Waters crater were classified by the geologic mappers of the H06 (De Hon et al. 1981) and H07 quadrangles (King and Scott, 1990) as "c5" class craters (with "c5" defined as the class that includes the morphologically and stratigraphically youngest craters on the surface of Mercury).

Waters crater and Kuiper crater are suitable for a direct comparison because they share a number of similarities, such as a young relative age and a certain quantity of external impact melt. Kuiper crater lies on the topographic rim of the preexisting Murasaki crater, and Waters crater similarly lies on the rim of an older unnamed impact basin. For this, the actual morphologic configuration of each of the two craters was influenced by preexisting topography, causing impact melt to be ejected out of the crater rims (Beach et al., 2012; D'Incecco et al., 2012, 2013; Hawke and Head, 1977; Ostrach et al., 2012).

Kuiper crater is located in a heavily cratered region of the Kuiper quadrangle. At shallow depths, its deposits directly overlap older deposits from Murasaki crater and, at greater depths, an alternation of intercrater plains and "plains and terra material" (De
Hon et al., 1981). The unit "plains and terra material" is described by De Hon et al. (1981) as "mostly cratered and intercrater plains materials, which may include some smooth plains and rough terra deposits", and it extends until Waters crater, which lies directly over these very ancient deposits (King and Scott, 1990). Waters crater is instead surrounded by a thin layer defined as "bright ray or halo material around or emanating from c5 craters", and was interpreted as fresh ejecta by King and Scott (1990).

$\mathrm{Al} / \mathrm{Si}$ and $\mathrm{Mg} / \mathrm{Si}$ ratios from the most recent XRS data (Weider et al., 2015) show that the surroundings of Kuiper crater are richer in Al than the surroundings of Waters crater, while Waters crater is beyond the southern limit of the high-Mg region. XRS data support the Mariner 10 morphologic observation that Waters crater is located on ancient deposits as the values $\mathrm{Al} / \mathrm{Si}$ and $\mathrm{Mg} / \mathrm{Si}$ near Waters are consistent with the average composition of intercrater plains and heavily cratered terrain materials (Weider et al., 2015).

An area of Mercury's surface which includes Waters crater was examined by Izenberg et al. (2014) using the three spectral parameters described in the previous section. They defined the ejecta of Waters crater as fresh crater materials, while they categorized the surrounding area as low-reflectance blue plains (LBP), using the same nomenclature as MDIS color units (Robinson et al. 2008; Denevi et al. 2009). Whitten et al. (2014) mapped a region of Mercury's surface that includes Waters crater. They defined its ejecta as crater materials, mapping its surroundings as intercrater plains, in partial modification of the nomenclature previously established by Mariner 10 authors (De Hon et al. 1981; King and 
Scott, 1990). The smooth plains mapped by Denevi et al. (2013) do not include Waters crater, Kuiper crater, or their respective surroundings. Thus, the LBP designation assigned by Izenberg et al. (2014) to the region surrounding Waters crater in their spectral Red-Green-Blue map is not consistent with the geological definition of LBP of Denevi et al. (2009).

\section{Methods and procedure}

To complement the unsupervised hierarchical clustering analysis technique used by D’Amore et al. (2013a,b) and Helbert et al. (2013), we here perform a direct cross-correlation between geological and spectral characteristics through independent geologic mapping and supervised spectral analysis. In contrast to the methods of Izenberg et al. (2014), in which spectral units were defined by spectral parameterization, we define units by identifying geological boundaries in image data and then performing a supervised spectral analysis of these units. Such a geologically supervised analysis can be very effective for a local scale spectral correlation. Our procedure is characterized by three main steps: 1) geologic classification of the two analyzed impact structures with related mapping; 2) extraction of the MASCS observations falling within each of the mapped units; and, 3) approximate reconstruction of the local scale stratigraphy beneath the two analyzed craters.

a

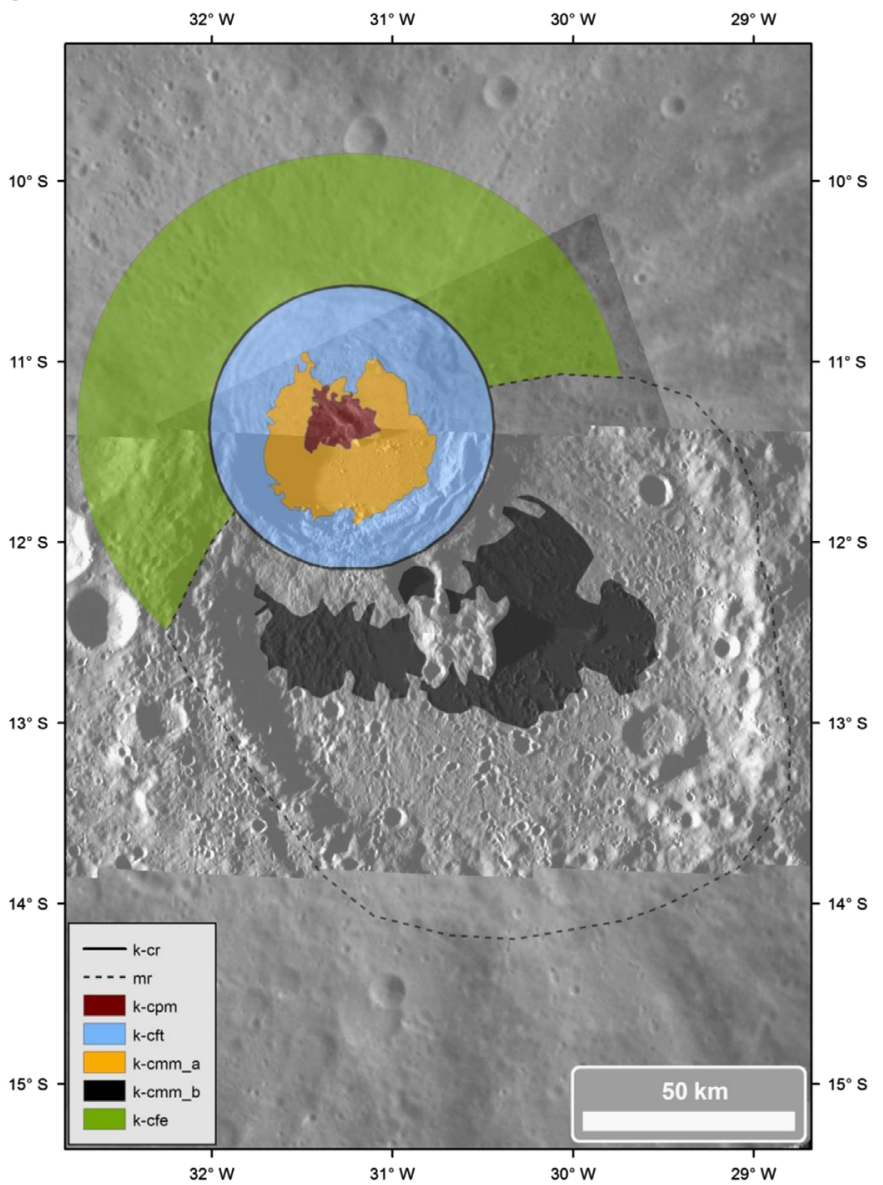

\subsection{Geologic mapping}

We defined the following units for both Waters (Fig. 2a) and Kuiper (Fig. 3a) craters: crater peak material (cpm), crater floor and terraces (cft), crater melt material located within the crater rim (cmm_a), crater melt material external to the crater rim (cmm_b). Despite MDIS NAC images show no unequivocal indication of a developed central peak at Waters crater, it is clear the presence of a proto-central peak as Waters crater is at the transition between simple and complex crater morphology.

Considering that previous studies on the distribution of proximal impact ejecta in the Solar System (Melosh, 1989; Osinski et al. 2011) showed that a layer of continuous fresh ejecta generally surrounds all the fresh impact craters within a distance between 1 and 2 crater radii from the crater rim, we defined an annulus extending from the crater rim until a distance of 1 crater radius for both craters. This annulus is mapped as the unit "crater fresh ejecta" ( $c f e$ ). The unit "cfe", excludes the areas partially covered by external impact melt ( $\mathrm{cmm} \_$b) because we interpret the external melt as a unit which postdates and covers the underlying "cfe". For this reason, the unit "cfe" is partially erased over both Waters and Kuiper craters.

Due to the particular topographic configuration of the two craters, we could not precisely distinguish wall deposits and slump deposits from floor deposits. Moreover, in the case of Waters

b

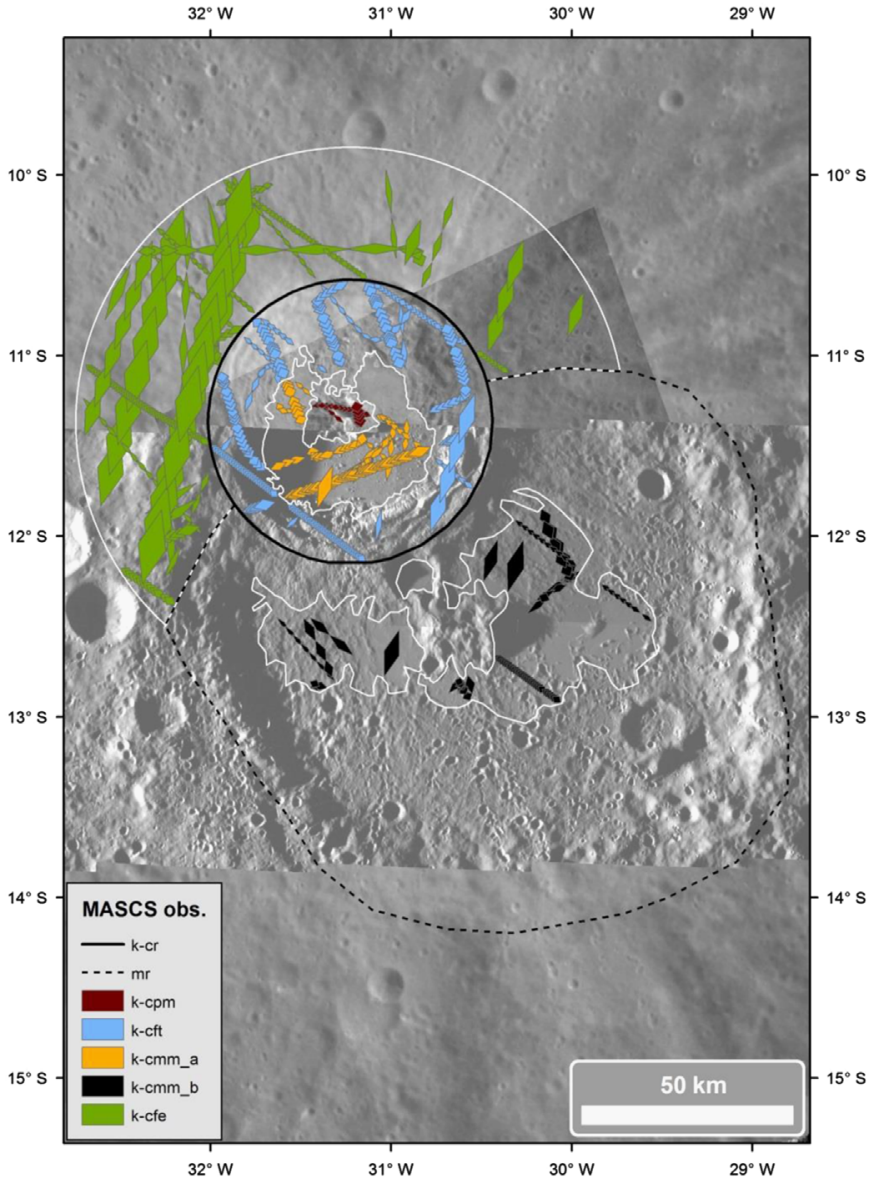

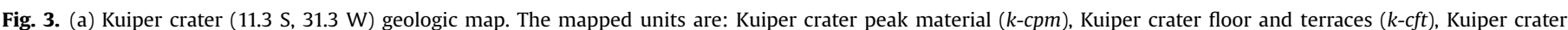

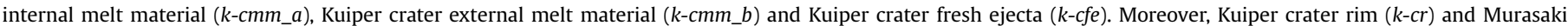

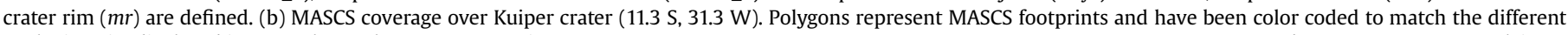

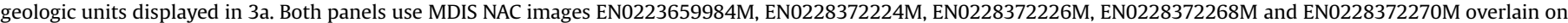
MDIS WAC image EW0223443634I as their background. 
crater, the simpler and bowl shaped morphology did not allow a real separation between wall and floor.

In order to facilitate the differentiation of the units of the two craters, we have added the prefix " $w$-" to the units mapped at Waters crater, while we have added the prefix " $k$-" to the units mapped at Kuiper crater. In this way, for instance, the unit cpm will be $w$-cpm for Waters crater and $k$-cpm for Kuiper crater.

We have defined an external reference area (era), centered at $2.4^{\circ} \mathrm{N}, 83.3^{\circ} \mathrm{W}$ (Figs. $1 \mathrm{a}$ and $4 \mathrm{a}$ ), that we use as a comparison for interpreting the spectral characteristics of the units mapped at Kuiper crater and Waters crater. This area, $100 \mathrm{~km} \times 70 \mathrm{~km}$ in size, is located between Kuiper crater and Waters crater, within a region previously mapped by King and Scott (1990) as intercrater plains. The reference spectra extracted from this region (Figs. 4b and 5-7) allow us to quantify relative spectral differences between the units mapped for the two craters.

For mapping consistency, we relate the nomenclature of our mapped units to that used by Mariner 10 mappers for the H06
Kuiper and Beethoven quadrangles (e.g. De Hon et al. 1981; King and Scott, 1990). This nomenclature is more properly suited to geologic mapping than the nomenclature more recently proposed by Denevi et al. (2009) and Denevi et al. (2013), which is instead based on the spectral properties of the defined units. However, the $w$-cmm_ $a$ and $w$-cmm_b units were not mapped by King and Scott (1990). The two units together form a lobate melt flow which moves from the internal $\left(w-c m m \_a\right)$ to the external $\left(w-c m m \_b\right)$ surface of Waters crater. As far as Kuiper crater is concerned, De Hon et al. (1981) mapped the units we identified respectively as $k$ $c m m \_a$ and $k-c m m \_b$, as "smooth plains materials". In particular, $k$ $c m m \_b$ is not a typical lobate flow extending from the internal to the external region of the crater of origin. Within the Kuiper crater's rim, deposits collapsed mostly from the north-western portion of the wall, and the maximum accumulation of $k-c m m \_a$ and the melt ejecta of $k-c m m \_b$ all point in the same SE direction. These factors indicate that Kuiper crater's SE margin collapses towards Murasaki crater. In fact, the whole $k$-cmm_b unit is a

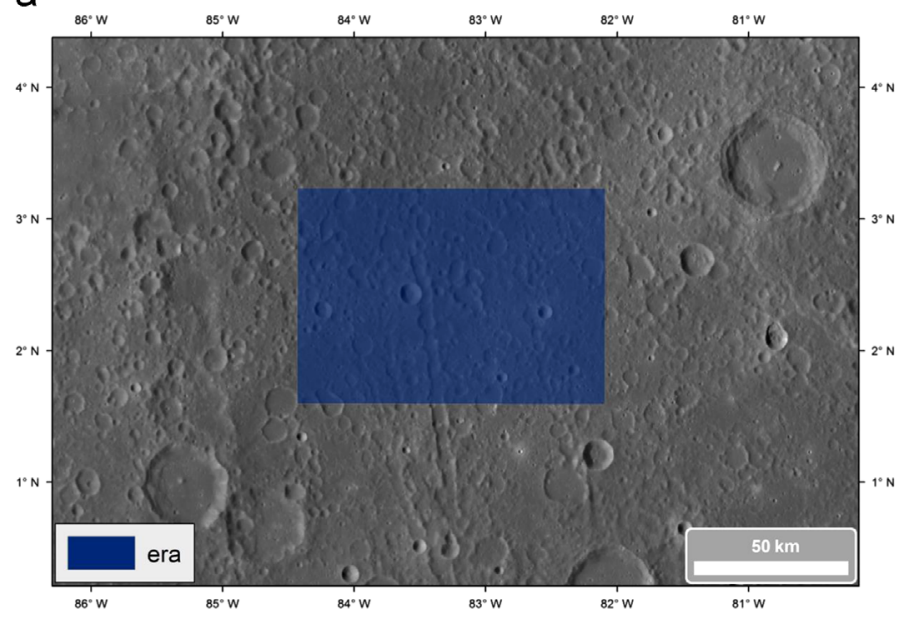

b

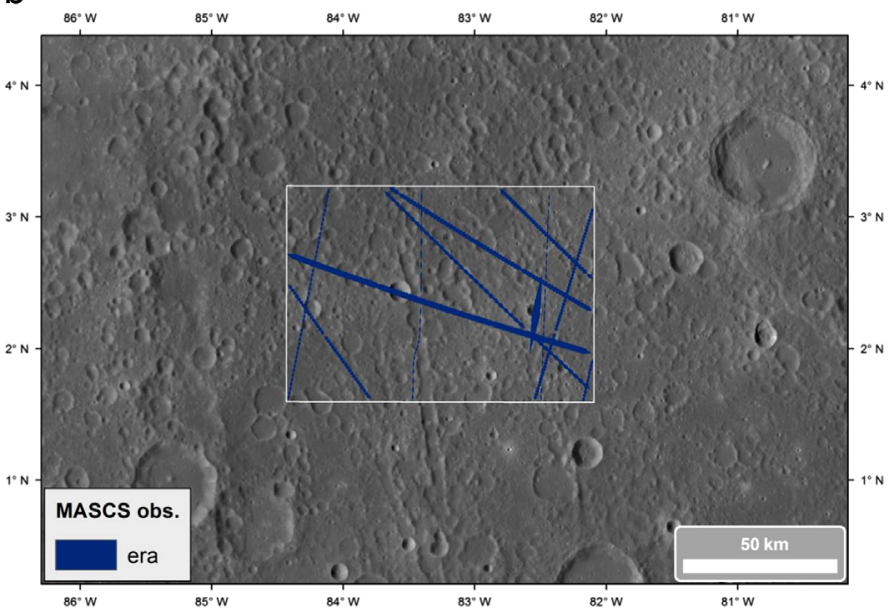

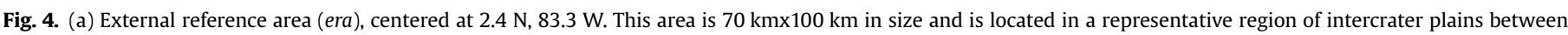
Waters crater and Kuiper crater. (b) MASCS coverage over the external reference area (era), centered at 2.4 N, 83.3 W. Polygons represent MASCS footprints.

a

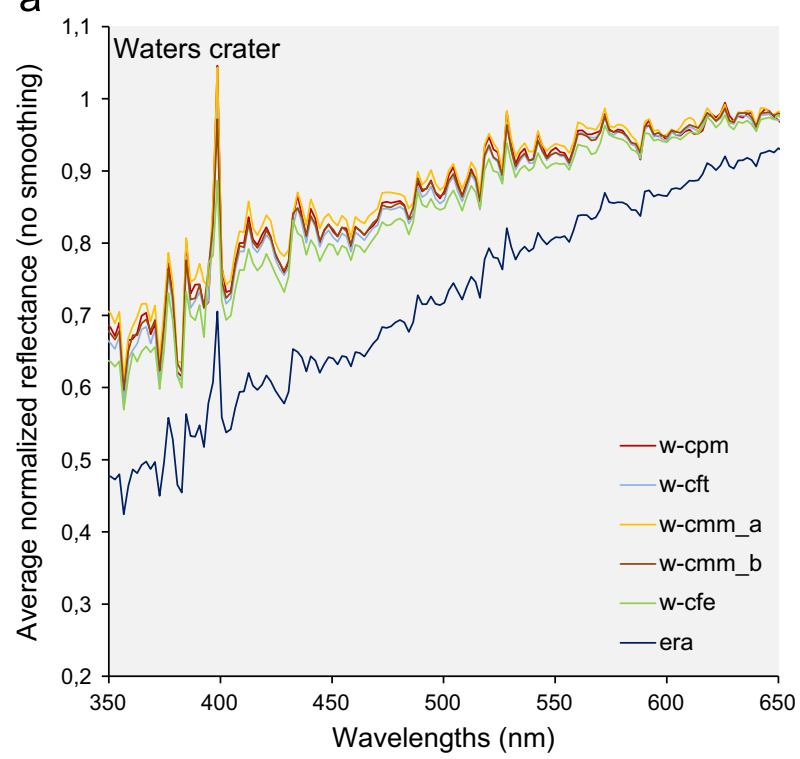

b

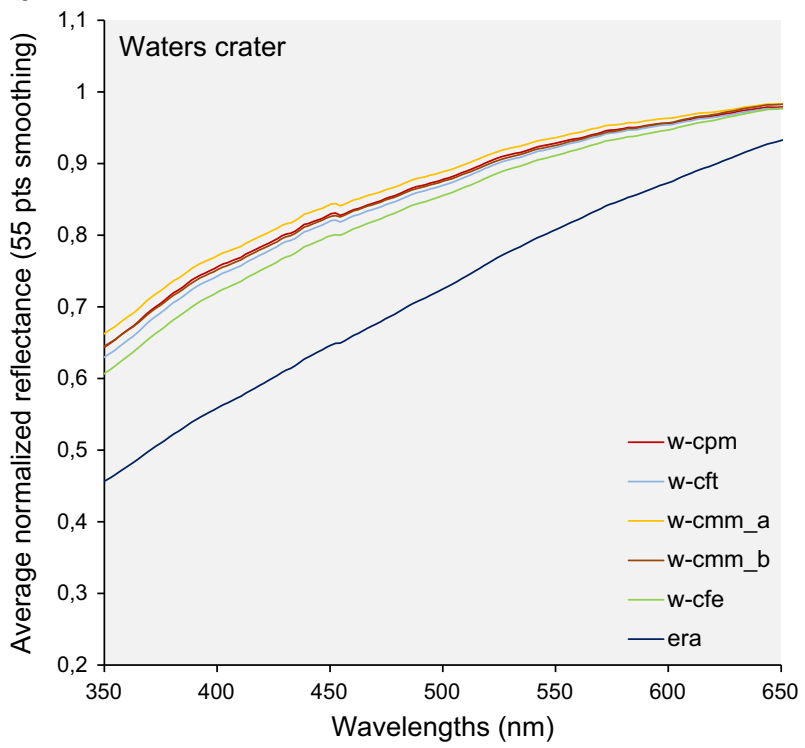

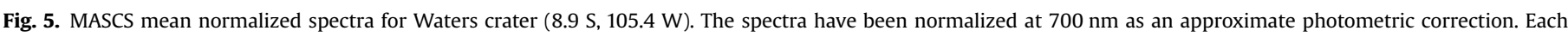

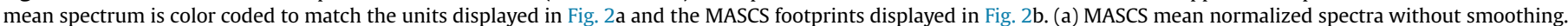
(b) MASCS mean normalized spectra smoothed with a 55 points sampling interval. 

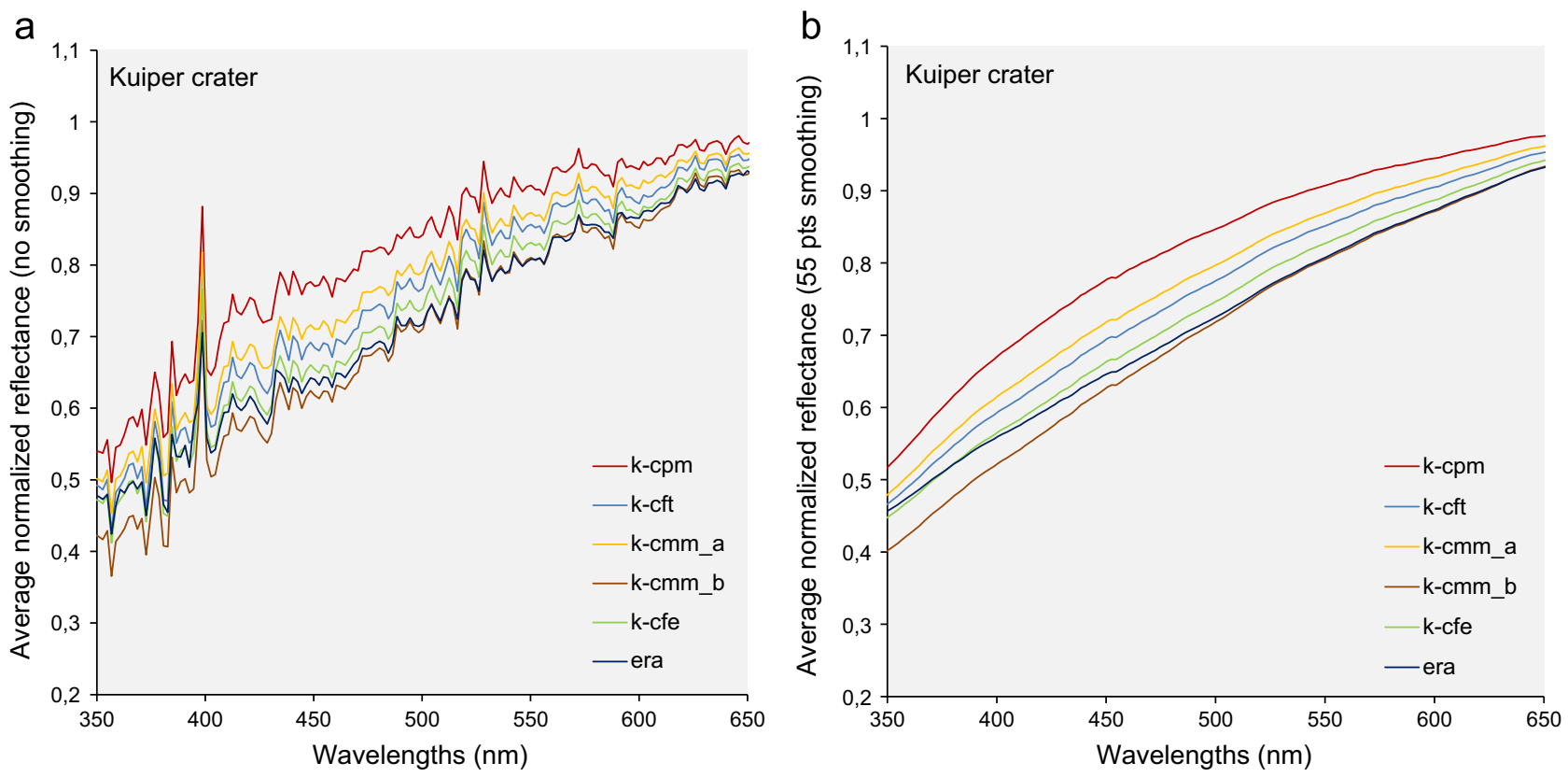

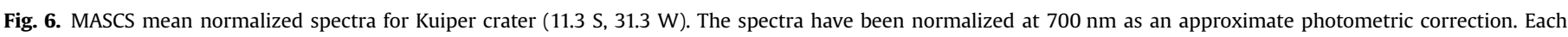

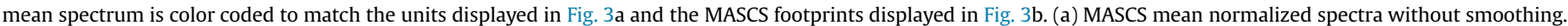
(b) MASCS mean normalized spectra smoothed with a 55 points sampling interval.

emplaced over the floor of Murasaki, and there is no trace of melt in other directions around the rim of Kuiper crater. This implies that $k-c m m \_b$ is just emplaced where it would be expected to be emplaced if $k$-cmm_b were impact melt flowing from Kuiper crater. Though we can't exclude a volcanic origin for $k-c m m \_b$ within Murasaki crater, there are no visible eruption vents to support a volcanic origin. For these reasons, we interpret $k$-cmm_b as an impact melt ejected at a certain distance from-rather than flowing as a continuous unit out of-the rim of Kuiper crater. In order to avoid confusion between $w$-cmm_b, that is a common lobate outflowed melt, and $k$-cmm_b, we represent these two units with different colors, respectively brown and black (Figs. 2a and 3a).

\subsection{MASCS observations selection procedure}

Exploiting the capabilities of specific spatial queries in the DLR MASCS database (D'Amore et al. 2013a,b; Helbert et al. 2013), we selected MASCS observations whose footprints are completely included within the boundaries of each of the units mapped at Waters crater (Fig. 2a and b), Kuiper crater (Fig. 3a and b) and the External Reference Area (Fig. 4a and b). We then calculated spectral slopes and extracted the absolute average reflectance in the $700-750 \mathrm{~nm}$ wavelength window. Before calculating the spectral slopes, we applied an additional filter to the data, selecting only the MASCS observations with incidence angle $<72^{\circ}$, instrument temperature between $10^{\circ} \mathrm{C}$ and $30^{\circ} \mathrm{C}$ and with average $700-$ $750 \mathrm{~nm}$ reflectance $>0$. To calculate the spectral slope, we normalized the spectra at $700 \mathrm{~nm}$. As our data were not photometrically corrected, we used this normalization as an approximate photometric correction that strongly reduces phase angle effects (D'Amore et al., 2013a,b). Using the filtered data, we calculated the mean values of normalized reflectance for all available observations at each wavelength. We iterated this procedure for each of the units and for the external reference area (era), getting a single mean normalized spectrum for each unit mapped over Waters crater (Fig. 5a) and over Kuiper crater (Fig. 6a). No clear absorption bands are discernible in the shown spectra. Thus, we focus our discussion on the analysis of the spectral slopes. However, the spectra in Fig. 5a and b exhibit relatively high noise, which may potentially affect the calculations of spectral slopes. For this reason, before calculating spectral slopes, we decided to apply a smoothing function with a sampling interval of 55 points to each mean normalized spectrum belonging to each unit of Waters crater (Fig. 5b) and Kuiper crater (Fig. 6b). We have then calculated two different slope values in \% for each smoothed mean spectrum: the first slope value was calculated in the $350-450 \mathrm{~nm}$ wavelength window (Fig. 7a and c), while the second value was calculated in the 450-650 nm wavelength window (Fig. 7b and d). We selected the upper limit of $650 \mathrm{~nm}$ for the second wavelength window in order to avoid getting too close to the normalization point at $700 \mathrm{~nm}$, since near the normalization point all spectra approximately converge to one, nullifying the relative differences in spectral slope occurring between the mapped units.

For extracting the average $700-750 \mathrm{~nm}$ reflectance, we have applied another filter. Since the average $700-750 \mathrm{~nm}$ reflectance is not photometrically corrected, we selected only observations with incidence angles between $25^{\circ}$ and $35^{\circ}$ and with emission angles between $40^{\circ}$ and $50^{\circ}$ (Fig. $7 \mathrm{a}$ and $\mathrm{b}$ ). While this may not remove all phase angle effects, it does eliminate the more extreme viewing geometries. The only exception is represented by the Waters crater internal melt material $\left(w-c m m \_a\right)$, since the only three MASCS observations falling within this unit were obtained at incidence angles of $46^{\circ}$ and emission angles between $32^{\circ}$ and $33^{\circ}$. We decided to include these observations in our analysis, though we will consider the viewing geometry limitations in our discussion.

However, over the small range of phase angles observed by the MASCS instrument, there is no evidence of a correlation between spectral slope and incidence, emission, or phase angles (Izenberg et al., 2014). Thus, in this work we base our conclusions mainly on observed differences in spectral slope occurring between the analyzed units; we discuss the values of average $700-750 \mathrm{~nm}$ reflectance only as a secondary parameter to be investigated in more detail once a photometric correction is available.

\subsection{Local scale stratigraphy beneath Waters crater and Kuiper crater}

The last step of our analysis is to estimate the relative thickness and depth of origin of the layers excavated by the impact events 

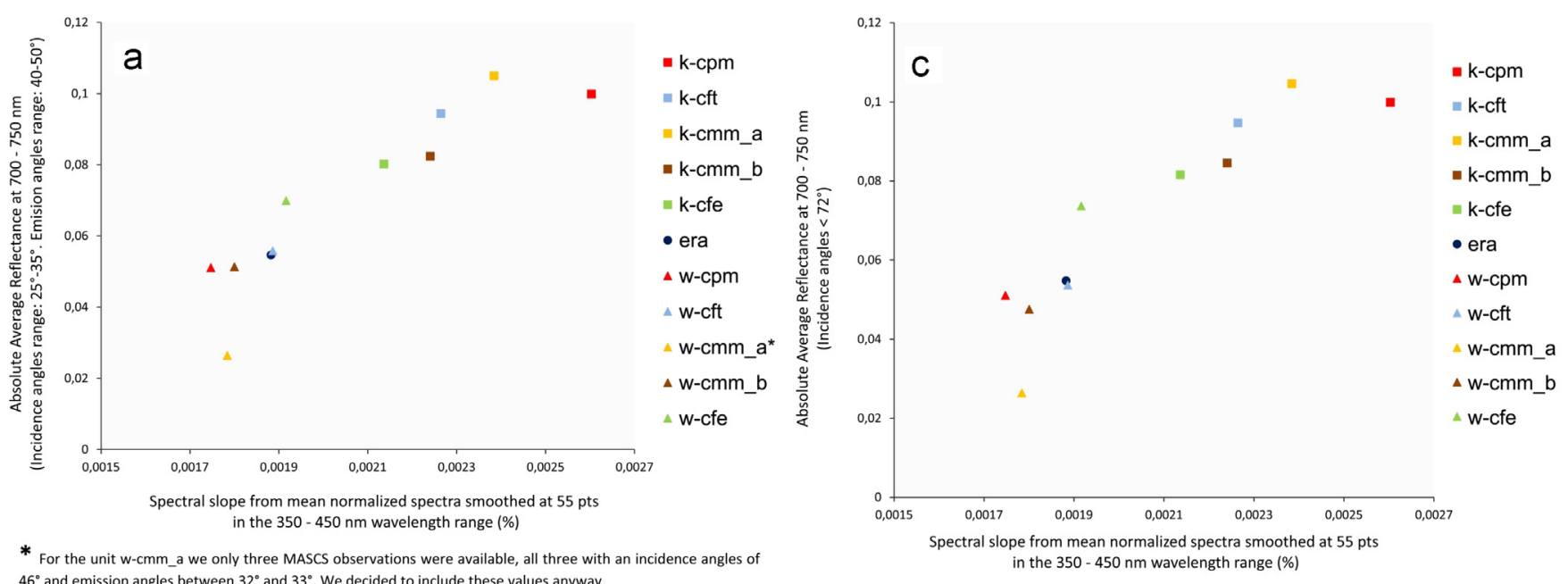

* For the unit w-cmm a we only three MASCS observations were available, all three with an incidence angles of

$46^{\circ}$ and emission angles between $32^{\circ}$ and $33^{\circ}$. We decided to include these values anyway.
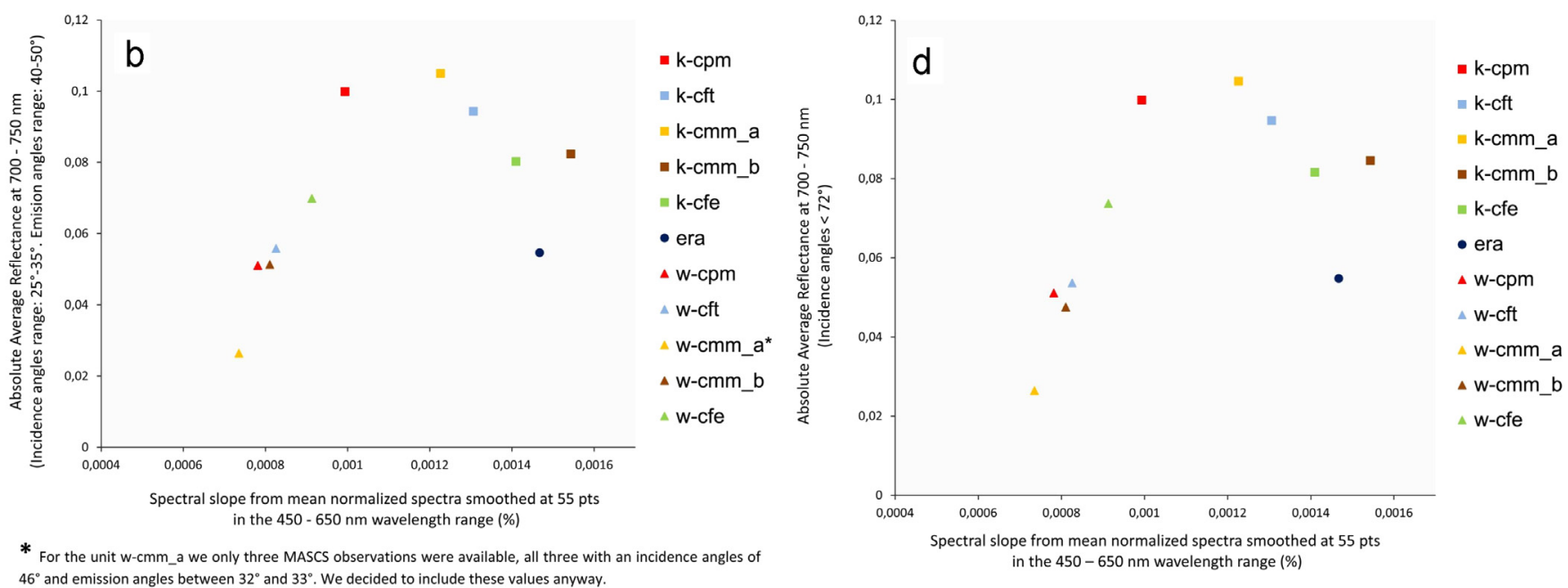

* For the unit w-cmm_a we only three MASCS observations were available, all three with an incidence angles of

$46^{\circ}$ and emission angles between $32^{\circ}$ and $33^{\circ}$. We decided to include these values anyway.

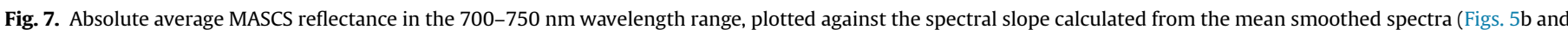

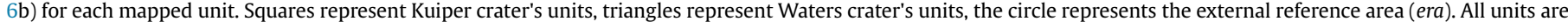

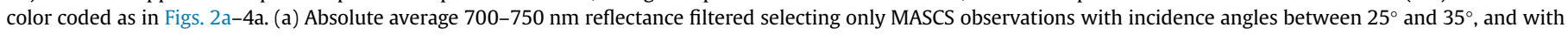

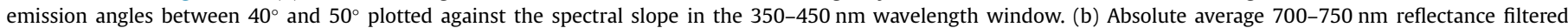

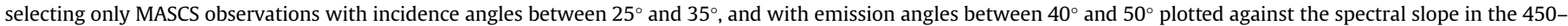

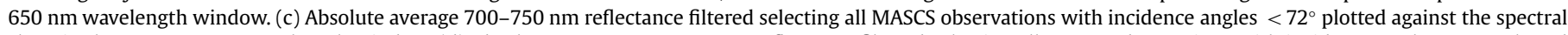

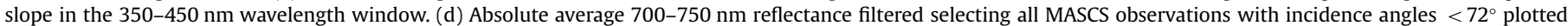
against the spectral slope in the $450-650 \mathrm{~nm}$ wavelength window.

which formed Waters and Kuiper craters. We apply similar methods to those of Ernst et al. (2010), who combined geological mapping with semi-analytical crater scaling rules to estimate the depth of origin of spectrally distinct surface material exposed by impact craters on Mercury. Considering that the maximum excavation depth of ejecta is approximately equal to one-tenth of the transient crater diameter $\left(D_{\mathrm{tc}}\right)$, they used the visible rim to rim diameter $\left(D_{\mathrm{r}}\right)$ to derive the transient crater diameter. Ernst et al. (2010) present three analytical methods for relating $D_{\mathrm{r}}$ to $D_{\mathrm{tc}}$ (Croft, 1985; Melosh, 1989; Holsapple, 1993), but selected the most recent of the three methods (Holsapple, 1993) for their calculations as it is the most comprehensive study and incorporated also experimental observations.

Ernst et al. (2010) also estimated the "maximum depth of melting", which is the maximum depth of origin of the melt material within and outside of impact craters such as Kuiper and Waters. One important observation made by Ernst et al. (2010) is that the maximum depth of melting can be taken as the minimum depth of origin for the central peaks, since central peaks are made of solid material which arises from greater depths directly penetrating the layer of more liquid impact melt.
The relationship between $D_{\mathrm{r}}, D_{\mathrm{tc}}$ and maximum excavation depth of ejecta we found for Kuiper and Waters craters is shown in Fig. 8a, while Fig. 8b shows the analytical relationship between $D_{\text {tc }}$ and the maximum depth of melting. For consistency with the work of Ernst et al. (2010), we have chosen the method from Holsapple (1993) for calculating $D_{\text {tc }}$ and consequently the maximum excavation depth of ejecta for the two craters and we used the method from Watters et al. (2009) for calculating the "maximum melting depth" (minimum depth of origin for the central peak) for Waters and Kuiper crater. These calculations have allowed us to partially reconstruct the local stratigraphy in the crust beneath the two craters, as it was before Waters crater (Fig. 9a and b) and Kuiper crater (Fig. 10) formations.

\section{Results}

From a first look at both the plots in Fig. 7a and b, we note that Waters crater's units and Kuiper crater's units are well localized in spectral reflectance space and not randomly arranged, even assuming that the average $700-750 \mathrm{~nm}$ reflectance is partially 
a

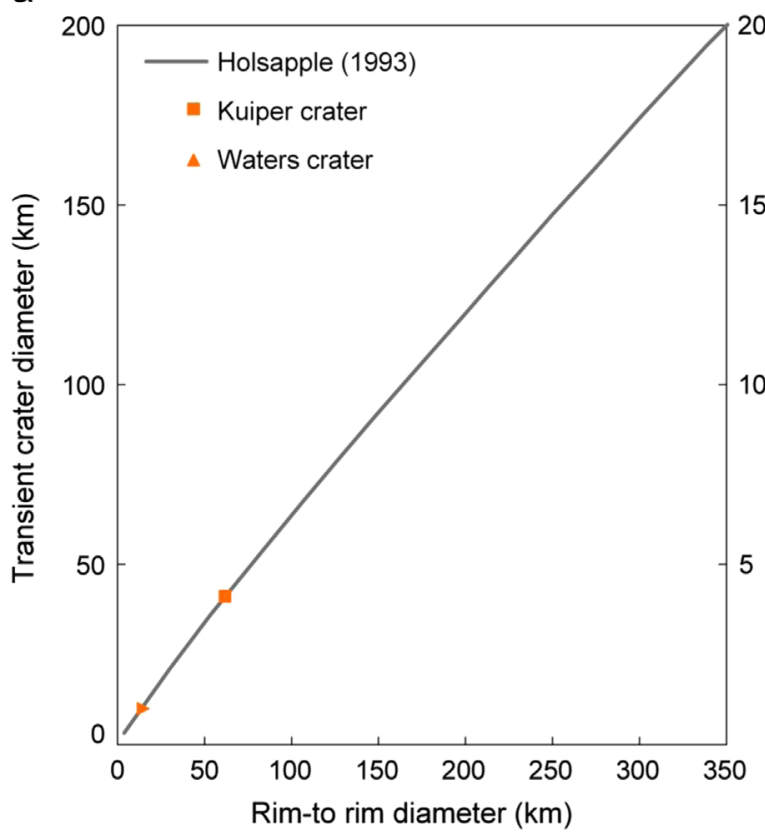

$\mathrm{b}$

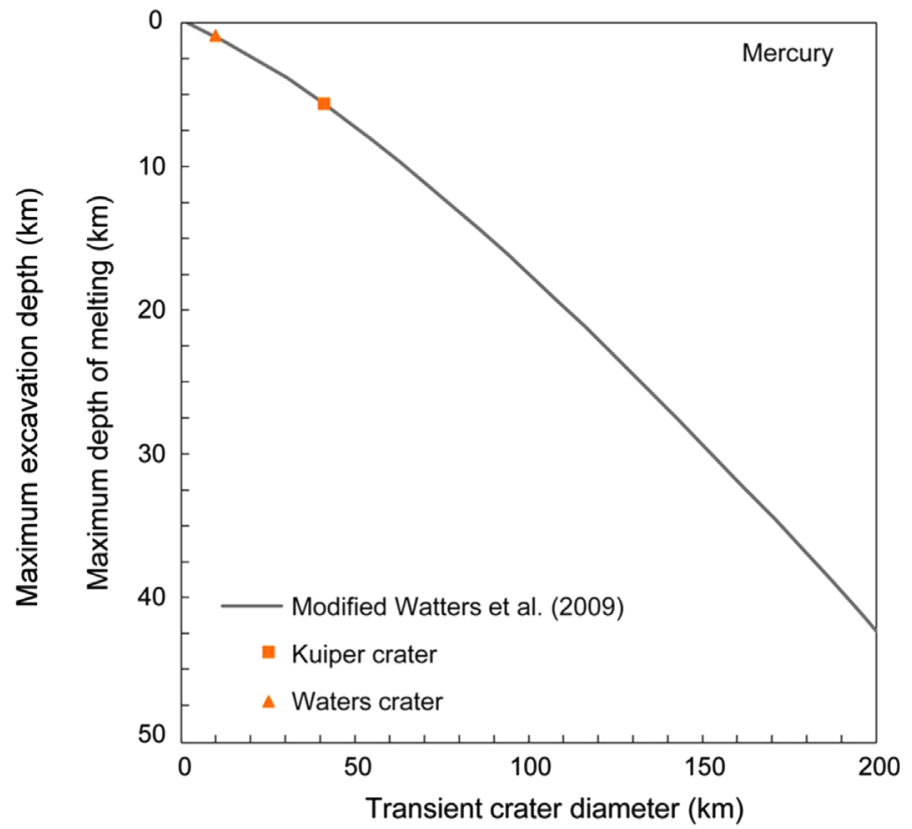

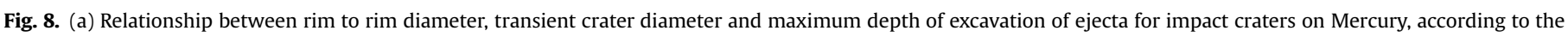

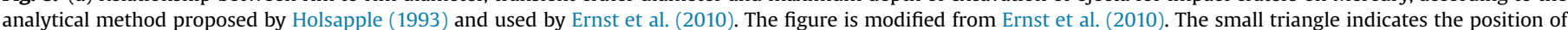

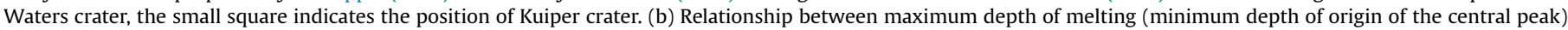

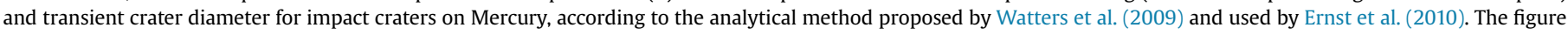
is modified from Ernst et al. (2010). The small triangle indicates the position of Waters crater, the small square indicates the position of Kuiper crater.

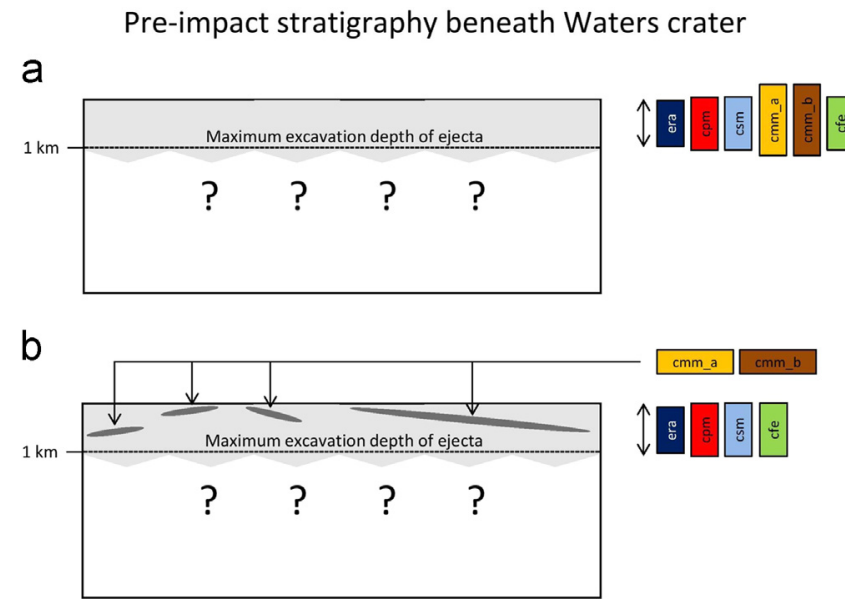

Fig. 9. Pre-impact stratigraphy beneath Waters crater, reconstructed using the analytical methods of Holsapple (1993) and Watters et al. (2009). (a) First possible scenario, where all of the units of Waters crater originate from the same surface layer, with an average composition very similar to that of the era unit (intercrater plains). (b) Second possible scenario, where $w$-cpm, $w$-cft and $w$-cfe would originate from a uniform layer with composition similar to that of the era unit, while the units $w$-cmm_a and $w$-cmm_b would originate from shallow intrusions of dark material with a composition different from that of the units $w$-cpm, $w$-cft, $w$-cfe and different from that of the era unit.

affected by phase angle effects. The units of Kuiper crater all lie up towards the upper right (high 700-750 nm reflectance and high $350-450 \mathrm{~nm}$ and $450-650 \mathrm{~nm}$ slope), while the units of Waters crater are all located towards the lower left (low 700-750 nm reflectance and low $350-450 \mathrm{~nm}$ and $450-650 \mathrm{~nm}$ slope) of the two plots in Fig. 7a and b. The era unit exhibits a spectral slope and average reflectance at $700-750 \mathrm{~nm}$ that is characteristic of typical intercrater plains. The units of the Kuiper crater show a 350-450 spectral slope and $700-750 \mathrm{~nm}$ reflectance higher than the era unit, while the units of Waters crater (except for $w$-cfe) display a

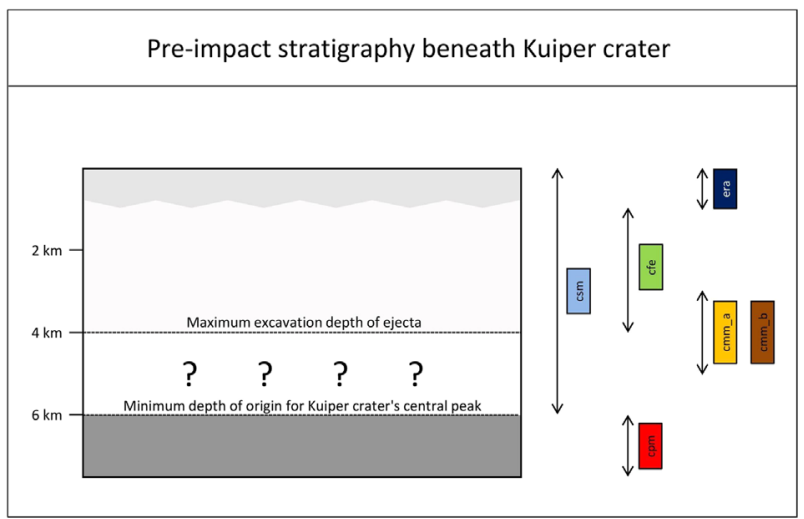

Fig. 10. Pre-impact stratigraphy beneath Kuiper crater, reconstructed using the analytical methods by Holsapple (1993) and Watters et al. (2009). The relative depth of origin of each unit mapped beneath Kuiper crater is displayed to the right of the stratigraphic column. The different scales of gray indicate material with different composition.

lower 350-450 spectral slope and a lower 700-750 nm reflectance.

Besides compositional variations and phase angle effects, the spectral differences between two or more materials can be caused by several factors. Space weathering acts reddening (steepening) the slope and decreasing the absolute reflectance of the spectra (Fischer and Pieters, 1994; Ernst et al., 2010). On the other hand, previous studies on the spectra of experimentally shocked enstatite in the 350-2500 nm wavelength range (Adams et al., 1979) and plagioclase feldspars in the $400-2500 \mathrm{~nm}$ wavelength range (Johnson and Hoerz, 2003), have shown that impact metamorphism induces an overall decreases in reflectance with increasing shock pressures, with only minor variations in the absorption bands or spectral slope. Finally, in the $700-750 \mathrm{~nm}$ wavelength range, reflectance decreases with increasing grain size (i.e., Hapke, 1993; Clark and Roush, 1984). Assuming that both 
Waters and Kuiper craters expose material relatively fresher and less mature than the surrounding intercrater plains (era unit), the position of the units of Waters crater on both Fig. $7 a$ and $b$ is consistent with space weathering being the dominant cause of the spectral differences observed between the deposits of Waters crater and the External Reference Area (era) deposits. The fresh deposits of Waters crater are generally characterized by spectral slope lower than or similar to that of the more mature deposits of the era unit (Fig. 7a and b), as would be expected if space weathering is the dominant process affecting the spectral slope, though we cannot exclude the presence of compositional heterogeneities.

Looking at the mapped units of Waters crater more in detail (Fig.7b), we notice that in the $450-650 \mathrm{~nm}$ wavelength range the crater's units exhibit significantly bluer spectral slopes than the era unit: in the case of $w$-cpm, w-cft and $w$-cfe units, this is most likely due to shorter exposure to space weathering effects. The absolute $700-750 \mathrm{~nm}$ reflectance of $w$-cpm, $w$-cft and $w$-cmm_b is generally similar to that of the era unit. This might indicate that the peak shock pressures reached during Waters crater's impact were not so high to strongly affect the spectral characteristics of these three units compared to era unit. Moreover, the spectral outputs of $w$-cft and $w-c m m \_b$ are not given by one single material, but most likely represent a mixture of different materials.

The unit $w$-cfe displays instead higher absolute reflectance than the era unit. Assuming that Waters crater's impact did not excavate deep into the shallow crust of Mercury, $k$-cfe might be composed of intercrater plains (era unit) material that has experienced low degree of impact metamorphism. In comparison with the progenitor regolith of intercrater plains (era unit), $w$-cfe is less mature and might have been even more finely powdered after the impact. This might explain the higher absolute reflectance of $w$-cfe compared to that of era unit.

A different argument can be made for $w$-cmm_a, which displays a lower spectral slope and a relatively lower absolute average $700-750 \mathrm{~nm}$ reflectance compared to the era unit (Fig. 7a and b). Since for $w$-cmm_a we have included absolute $700-750 \mathrm{~nm}$ reflectance values with incidence angles of $46^{\circ}$ and emission angles between $32^{\circ}$ and $33^{\circ}$ - we tested whether phase angle effects are likely to be the cause of the low reflectance of $w$ cmm_a. In particular, we applied a much broader incidence angle filter of $<72^{\circ}$ also to absolute mean $700-750 \mathrm{~nm}$ reflectance. As illustrated in Fig. $7 \mathrm{c}$ and $\mathrm{d}$, the relative positions of the mapped units remain similar to those in the corresponding plots in Fig. 7a and $\mathrm{b}$. This suggests that the values of absolute reflectance are not dramatically affected by the variations in incidence angle and emission angle across the two analyzed craters and across the era unit. Hence, assuming that phase angle effects are not involved, the low reflectance of $w$-cmm_a can be caused by textural changes with genesis of glasses after the melting process (i.e., Johnson and Hoerz, 2003), without any direct relation between crystal size and mineral species of the pro-genitor material of $w$-cmm_a. In this case, all the units of Waters crater would originate from the same surface layer, with an average composition very similar to that of the era unit (intercrater plains) (Fig. 9a).

However, given its extremely low spectral slope and absolute 700-750 nm reflectance, we cannot either exclude a case where $w$-cmm_a originates from relatively shallow intrusions of dark material, possibly LRM, compositionally different from the surrounding intercrater plains (era unit) (Fig. 9b). In this case, Waters units $w$-cmm_ $a$ and $w$-cmm_b would thus represent the compositional continuum of a single unit, where the spectral differences we observe between $w$-cmm_ $a$ and $w$-cmm_b would be mainly due to the greater mixing of $w$-cmm_b with the external surface deposits such as $w$-cfe and intercrater plains (era unit). Hence, $w$ $c m m \_a$ should display spectral characteristics more consistent with the real composition of Waters crater impact melt than $w$ $c m m \_b$.

The interpretation of the spectral characteristics of the units mapped across Kuiper crater is made more challenging and intriguing by the larger size and penetration depth of this crater Unlike the units at Waters crater, the units of Kuiper crater display similar or higher absolute relative $700-750 \mathrm{~nm}$ reflectance to the era unit (Fig. 7a and b). Overall, Kuiper's normalized spectra display a generally redder slope than the external reference area in the $350-450 \mathrm{~nm}$ window, while they display a generally bluer slope than the external reference area in the 450-650 nm wavelength window. More specifically, in the $350-450 \mathrm{~nm}$ wavelength window all units of Kuiper crater show a spectral slope redder than the era unit, with $k$-cpm being the unit with the largest deviation from the spectral slope of the era unit (Fig. 7a). In the $450-650 \mathrm{~nm}$ wavelength window, $k-\mathrm{cmm} \_b$ is the only unit displaying slightly redder spectral slope than that of the era unit (Fig. 7b). During the stratigraphic and compositional interpretation of the units of Kuiper crater we will principally refer to the slope values in the $350-450 \mathrm{~nm}$ wavelength range, since this window is farther from the normalization point $(700 \mathrm{~nm})$.

As in the case of our analysis of Waters crater, we apply the same logic that given two materials with a similar starting composition, space weathering acts to redden (steepen) and often darken the spectra of the more mature material (Fischer and Pieters, 1994; Ernst et al., 2010). Kuiper crater's deposits are surely less mature than the surrounding intercrater plains (era unit), but the spectral slopes of Kuiper crater's units in the $350-450 \mathrm{~nm}$ wavelength range are much higher than the spectral slope of the era unit (Fig. 7a). This suggests that space weathering cannot be the dominant process producing the differences in spectral slopes between the deposits of Kuiper crater and the era unit. Rather, this may imply that Kuiper crater excavated material that is compositionally distinct from the intercrater plains (era unit). Additional evidence for compositional heterogeneities between the units exposed by Kuiper crater and the surrounding intercrater plains (era unit) can be found by examining the individual units at Kuiper crater.

The $k$-cpm unit is composed by the deepest material uplifted during the impact that formed Kuiper crater. This unit displays a much higher 700-750 $\mathrm{nm}$ reflectance than the era unit, as shown in Fig. 7a and b. The high reflectance, spectral slope, and depth of origin of this material suggests that the process which caused the observed spectral configuration of $k$-cpm was not space weathering. Impact metamorphism might play a role in determining the final spectral output of $k$-cpm. However, on the basis of previous studies (i.e., Adams et al., 1979; Johnson and Hoerz, 2003), if the metamorphosed $k$-cpm unit would be characterized by the same composition as the powdered regolith of the era unit, it should display absolute 700-750 reflectance lower than that of the era unit. For this reason we infer that $k$-cpm is compositionally different from the surrounding intercrater plains (era unit). A spectrally comparable unit, characterized by relatively high albedo and relatively high spectral slope, has been identified and named red material (RM) on the basis of Mariner 10 (Rava and Hapke, 1987; Dzurisin, 1977; Schultz, 1977), and MESSENGER (Robinson et al., 2008; Murchie et al., 2008; Head et al., 2008; Blewett et al., 2009; Kerber et al., 2009) data.

Like $k$-cpm, $k$-cmm_a also displays higher absolute 700-750 nm reflectance than the era unit and significant variability in spectral slope as its mean normalized spectrum approaches the normalization point at $700 \mathrm{~nm}$. The $k-\mathrm{cmm}_{-} a$ unit originated at shallower depths and likely experienced even higher shock pressures than $k$ cpm. Johnson and Hoerz (2003) demonstrated that, for the same pro-genitor material, reflectance at extremely high and melt generating shock pressures (like for $k-\mathrm{cmm}_{-} a$ ) should be expected 
to be lower than reflectance at lower shock pressures that only trigger metamorphism without noticeable melting (like for $k$-cpm). As $k$-cmm_a is characterized by absolute $700-750 \mathrm{~nm}$ reflectance that is even slightly higher than that of $k$-cpm, this implies that $k$ $c m m_{-} a$ could be compositionally different from the era unit, as well as from $k$-cpm. Alternatively, $k$-cmm_a might be composed by a mixture between $k$-cpm and other material that is compositionally different from $k$-cpm. However, texture might play a role as well. The MDIS color unit "high-reflectance red plains" (HRP), which corresponds with many of the smooth plains on Mercury (Robinson et al. 2008; Denevi et al. 2009), exhibits spectral characteristics similar to the spectral features of the unit $k$-cmm_a.

Similar to $w$-cmm_a and $w$-cmm_b, the spectral differences between $k$-cmm_a and $k-c m m \_b$ may be caused by increased mixing with the surrounding surface materials (era and $k$-cfe units). Together with $k$-cfe, $k$-cmm_b has an average $700-750 \mathrm{~nm}$ reflectance that is more similar to that of the era unit. Though $k$ $c m m \_b$ was mapped to represent the external impact melt of Kuiper crater, MASCS footprints partially include some $k$-cfe deposits and the older (more mature) external deposits from Murasaki crater's floor. The MASCS resolution does not allow small-scale variations in surface materials to be discerned, especially if we try to spectrally differentiate melt veneers (like for $k$ $c m m \_b$ ) from other surrounding materials. Moreover, the lower thickness of $k$-cmm_b (characterized by very thin melt flows, ponds and veneers), compared to the higher thickness of $k$-cmm_a, may negatively affect the reliability of the spectral output of $k$ $c m m \_b$. For this reason, the spectral characteristics of $k$-cmm_b should not be directly linked to compositional heterogeneities resulting from a single geologic unit. Geologically, $k-\mathrm{cmm} \_b$ should in fact represent a compositional continuum with the $k$-cmm_a. Hence, we infer the same depth of origin and composition for both $k$-cmm_a and $k$-cmm_b (Fig. 7a).

Of all units mapped in Kuiper crater, $k$-cfe is spectrally the most similar to the era unit (Fig. 7a and b). However, it is important to note that the spectral slope of $k$-cfe remains (as for all the other units of Kuiper crater) considerably higher in the $350-450 \mathrm{~nm}$ wavelength range, despite being very similar to that of era unit in the $450-650 \mathrm{~nm}$ range. The absolute $700-750 \mathrm{~nm}$ reflectance of $k$ $c f e$ is lower than that of the other units of Kuiper crater, but higher than that of the era unit. This implies that, as for the other units of Kuiper crater, impact metamorphism cannot be the dominant process in determining the observed spectral differences between $k$-cfe and the era unit (Adams et al., 1979; Johnson and Hoerz, 2003). Similarly, if grain-size effects would be the dominant process affecting the observed spectral differences between $k$-cfe and era unit, $k$-cfe should display lower reflectance than the era unit since the latter is likely made up of finely powdered regolith whereas the former is composed by fragmental material ejected immediately after the impact. As we observe the opposite situation, we exclude also the grain-size effects and we must infer a compositional difference between $k$-cfe and era units. It is not possible to determine if $k$-cfe and $k$-cpm are compositionally different since the $k$-cfe material could acquire a different 700-750 reflectance with respect to $k$-cpm on the basis of the diverse metamorphic degree (i.e. higher metamorphism=lower reflectance) and texture (i.e. finer grain size $=$ higher reflectance).

The spectral characteristics of $k$ - $c f t$, as for $k-c m m \_b$, are unlikely to represent a single distinct composition that was exposed in the impact event. Impact craters walls usually expose the different subsurface layers penetrated by the impact, thus the spectral characteristics of $k$-cft are interpreted as a mixture of the spectral features of the different excavated layers exposed at the crater wall. The relative position of $k$-cft in the two plots of Fig. $7 \mathrm{a}$ and $\mathrm{b}$ appears to be consistent with our interpretation.
Building on the work of Ernst et al. (2010), and given the spectral characteristics of the mapped units, we approximated the vertical stratigraphy beneath Waters crater and Kuiper crater. Using the same analytical methods as Ernst et al. (2010), we calculated a maximum excavation depth of ejecta of $\sim 1 \mathrm{~km}$ for Waters crater and $\sim 4.1 \mathrm{~km}$ for Kuiper crater (Holsapple, 1993), while we calculated a maximum melting depth (minimum depth of origin for the central peak) of $\sim 1 \mathrm{~km}$ for Waters crater (Figs. 8 and $9 \mathrm{a}$ and $\mathrm{b}$ ) and $\sim 6 \mathrm{~km}$ for Kuiper crater (Watters et al. 2009), as displayed in the Fig. 8a and b and 10.

On the basis of our spectral study, we propose that at least two layers with distinctive composition are present beneath Kuiper crater (Fig. 10). In particular we propose two layers beneath the relatively thin surface coverage of intercrater plains. The middle layer, which may extend to a depth of $\sim 4.1 \mathrm{~km}$, may have a distinct composition or may represent a mixed composition between that of the overlying and underlying layers. The $k$-cfe unit possibly originated from this layer. The depth of $\sim 6 \mathrm{~km}$ represents the maximum melting depth and also the minimum depth of origin for $k$-cpm. Thus, we assume that $k$-cmm_ $a$ and $k$-cmm_b originated from the range of depths between $\sim 4.1$ and $\sim 6 \mathrm{~km}$. Beneath the depth of $\sim 6 \mathrm{~km}$ (minimum depth of origin for the central peak of Kuiper crater), we are not able to constrain any other limit. From the analysis of the spectral features of $k$-cpm, we infer that material at this depth is characterized by a different composition than surface intercrater plains (era unit). In contrast, the spectral differences observed between $k$-cpm, $k$-cmm_ $a$ and $k$-cfe do not need to necessarily reflect compositional heterogeneities, as they might be at least partially attributed to other factors like the different grain size and the different shock pressures experienced by these materials during and after the impact process.

\section{Discussion}

The present study uses geologic interpretation and spectral analysis to provide a local scale characterization of two fresh impact craters of Mercury. The spectral analysis highlighted striking differences between Waters crater units and Kuiper crater units: the first being characterized by lower spectral slope and average 700-750 $\mathrm{nm}$ reflectance than the second. Furthermore, Kuiper crater's mean spectra (Fig. 6a and b) display a redder spectral slope than Waters crater's mean spectra over both the analyzed wavelength windows, while they display a spectral slope redder than the mean spectrum of the era unit in the 350-450 nm wavelength window and a slope bluer than the mean spectrum of the era unit in the 450-650 nm wavelength window. The spectral differences between the units mapped on Waters crater and the surrounding intercrater plains (era unit) do not necessarily need to be linked to compositional heterogeneities and can be explained assuming the dominance of other factors like space weathering and shock metamorphism. However, given the extremely low absolute 700-750 $\mathrm{nm}$ reflectance and spectral slope of $w$-cmm_a, we cannot exclude the occurrence of compositional heterogeneities between this unit and the era unit. For this reason we proposed two different scenarios. A first scenario where Waters crater impact melt $\left(w-c m m \_a\right.$ and $\left.w-c m m \_b\right)$ is compositionally homogeneous with the other units mapped over Waters crater and with the surrounding intercrater plains (unit era). A second scenario where Waters crater's impact melt (units $w$-cmm_ $a$ and $w$ $c m m \_b$ ) is compositionally different from the other units of Waters crater and from the surrounding intercrater plains. In the latter case, we suggest a similarity between with the MDIS color LRM unit (Robinson et al. 2008; Denevi et al. 2009) and the Waters crater impact melt. 
Kuiper crater's units display instead a much more variable spectral slope, as all its units in the $350-450 \mathrm{~nm}$ range are characterized by much higher values than that of the era unit, while almost the opposite happens in the $450-650 \mathrm{~nm}$ range. Given that a) spectral slope increases with space weathering (Fischer and Pieters, 1994), b) in the 700-750 nm range, absolute reflectance of experimentally shocked impact deposits generally decreases with increasing shock pressures (Adams et al., 1979; Johnson and Hoerz, 2003), and c) in the $700-750 \mathrm{~nm}$ range, absolute reflectance decreases with increasing grain size, we assume the occurrence of compositional heterogeneities between the units of Kuiper crater (in particular $k$-cpm, $k$-cmm_a and $k$-cfe) and the surrounding intercrater plains (era unit). We also infer the possible occurrence of compositional heterogeneities between $k$-cpm, $k$-cmm_ $a$ and $k$ $c f e$. However, we cannot exclude that $k$-cpm, $k$-cmm_ $a$ and $k$-cfe are characterized by materials of the same compositions looking spectrally different due to Kuiper-impact and post-impact processes (impact melting and metamorphism).

\section{Conclusions}

The geologically supervised spectral analysis over Waters and Kuiper craters identified spectral and compositional heterogeneities in the shallow crust of Mercury. In particular, this analysis clearly indicated the occurrence of compositional heterogeneities between all materials exposed by Kuiper crater and the surrounding intercrater plains. Two intriguing units, $k-c m m \_a$ and $w$-cmm_a, show spectral characteristics comparable to those of HRP and LRM units, respectively, as identified by Denevi et al. (2009). The higher spectral resolution of the future ESA BepiColombo mission will provide an even deeper look into the crustal properties of Mercury, with its Spectrometers and Imagers for Mercury Planetary Orbiter (MPO) BepiColombo Integrated Observatory System (SIMBIO-SYS) and Mercury Thermal Infrared Spectrometer (MERTIS) instruments. Both SIMBIO-SYS and MERTIS will allow discerning with improved precision among the various factors (i.e., chemical composition, texture, degree of metamorphism) affecting the spectral output of materials within the shallow crust of Mercury, especially those exposed by impact craters. Waiting for the new BepiColombo dataset, we are currently extending this geologically supervised procedure to include many more fresh impact craters in order to realize a global scale stratigraphic investigation of the shallow crust of Mercury using the MDIS dataset and the capabilities of the DLR MASCS database.

\section{Acknowledgments}

We gratefully acknowledge the MESSENGER team for its scientific support and constant review provided during all stages of development of the present manuscript.

We gratefully acknowledge the "Deutscher Akademischer Austauschdienst" (DAAD) (Code no. A/11/90936) for the financial support and for other allowances provided during all the duration of this scientific work.

\section{References}

Adams, J.B., Horz, F., Gibbons, R.V., 1979. Effects of shock-loading on the reflectance spectra of plagioclase, pyroxene, and glass. Lun. Planet Sci. Conf. 10, 1-3.

JR: Beach, M.J. et al., 2012. The influence of preexisting topography on the distribution of impact melt on Mercury. In: Proceedings of the 43rd Lunar Planetary Science Conference. p. 1335 abstract.

Blewett, D.T., Robinson, M.S., Denevi, B.W., Gillis-Davis, J.J., Head, J.W., Solomon, S C., Holsclaw, G.M., McClintock, W.E., 2009. Multispectral imaging of Mercury from the first MESSENGER flyby: analysis of global and regional color trends. Earth Planet Sci. Lett. 285, 272-282. http://dx.doi.org/10.1016/j. epsl.2009.02.021.

Blewett, D.T., Denevi, B.W., Robinson, M.S., Ernst, C.M., Purucker, M.E., Solomon, S C., 2010. The apparent lack of lunar-like swirls on Mercury: Implications for the formation of lunar swirls and for the agent of space weathering. Icarus 209 239-246.

Blewett, D.T., Coman, E.I., Hawke, B.R., Gillis Davis, J.J., Purucker, M.E., Hughes, C.G., 2011. Lunar swirls: examining crustal magnetic anomalies and space weathering trends. J. Geophys. Res. 116, E02002. http://dx.doi.org/10.1029/ 2010JE003656.

Blewett, D.T., Vaughan, W.M., Xiao, Z., Chabot, N.L., Denevi, B.W., Ernst, C.M., Helbert, J., D’Amore, M., Maturilli, A., Head, J.W., Solomon, S.C., 2013. Mercury's hollows: constraints on formation and composition from analysis of geological setting and spectral reflectance. J. Geophys. Res. Planets 118, 1013-1032. http: //dx.doi.org/10.1029/2012JE004174.

Byrne, P.K. et al. 2015. Near-synchronous end to global-scale effusive volcanism on Mercury. In: Proceedings of the 46th Lunar Planetary Science Conference. p. 1731, abstract.

Clark, R.N., Roush, T.L., 1984. Reflectance spectroscopy: ouantitative analysis techniques for remote sensing applications. J. Geophys. Res. 89, 6329-6340.

Croft, S.K., 1985. The scaling of complex craters. J. Geophys. Res. 90, C828-C842.

Denevi, B.W., Robinson, M.S., Solomon, S.C., Murchie, S.L., Blewett, D.T., Domingue, D.L., McCoy, T.J., Ernst, C.M., Head, J.W., Watters, T.R., Chabot, N.L., 2009. The evolution of Mercury's crust: a global perspective from MESSENGER. Science 324, 616-618.00

Denevi, B.W., Ernst, C.M., Meyer, H.M., Robinson, M.S., Murchie, S.L., Whitten, J.L., Head, J.W., Watters, T.R., Solomon, S.C., Ostrach, L.R., Chapman, C.R., Byrne, P.K. Klimczak, C., Peplowski, P.N., 2013. The distribution and origin of smooth plains on Mercury. J. Geophys. Res. Planets 118, 891-907. http://dx.doi.org/10.1002/ jgre.20075.

De Hon, R.A., Scott, D.H., Underwood, J.R., 1981. Geologic Map of the Kuiper (H-6) Quadrangle of Mercury, I-1233. USGS, Reston, VA.

D'Amore, M. et al. 2013a. Unsupervised clustering analysis of spectral data for the Rudaki Area on Mercury. In: Proceedings of the 44th Lunar Planetary Science Conference, p. 1896.

D'Amore, M. et al. 2013b. Exploiting the Mercury surface reflectance spectroscopy dataset from MESSENGER: making sense of three million spectra. In: Proceedings of the 44th Lunar Planetary Science Conference, p. 1900.

D'Incecco, P. et al. 2012. Kuiper crater on Mercury-An opportunity to study recent surface weathering trends with MESSENGER. In: Proceedings of the 43rd Lunar Planetary Science Conference, p. 1815.

D'Incecco, P. et al. 2013. Spectral properties and geology of two impact craters on Mercury. In: Proceedings of the 44th Lunar Planetary Science Conference, p. 1499.

Dzurisin, D., 1977. Geologic Significance of Photometric Variations on Mercury. (Ph.D. thesis), Part 2. California Institute of Technology, Pasadena.

Ernst, C.M., Murchie, S.L., Barnouin, O.S., Robinson, M.S., Denevi, B.W., Blewett, D.T., Head, J.W., Izenberg, N.R., Solomon, S.C., Roberts, J.H., 2010. Exposure of spectrally distinct material by impact craters on Mercury: Implications for global stratigraphy. Icarus 209, 210-223.

Fischer, E.M., Pieters, C.M., 1994. Quantification of lunar surface mineralogy and chemistry from remote spectroscopic measurements: Removing the optical effects of space weathering, paper presented at 10th Thematic Conference on Geologic Remote Sensing, San Antonio, TX, May 9-12.

Gault, D.E., Guest, J.E., Murray, J.B., Dzurisin, D., Malin, M.C., 1975. Some comparisons of impact craters on Mercury and the. Moon J. Geophys. Res. 80 2444-2460.

Goudge, T.A., Head, J.W., Kerber, L., Blewett, D.T., Denevi, B.W., Domingue, D.L., Gillis-Davis, J.J., Gwinner, K., Helbert, J., Holsclaw, G.M., Izenberg, N.R., Klima, R. L., McClintock, W.E., Murchie, S.L., Neumann, G.A., Smith, D.E., Strom, R.G., Xiao, Z., Zuber, M.T., Solomon, S.C., 2014. Global inventory and characterization of pyroclastic deposits on Mercury: new insights into pyroclastic activity from MESSENGER orbital data. J. Geophys. Res. Planets 119, 635-658. http://dx.doi org/10.1002/2013JE004480.

Grolier, M.J., Boyce, J.M., 1984. Geologic map of the Borealis Region (H-1) of Mercury, I-. USGS, Reston, VAUSGS, Reston, VA.

Guest, J.E., Greeley, R., 1983. Geologic map of the Shakespeare (H-3) Quadrangle of Mercury, I-1408. USGS, Reston, VA.

Hapke, B., 1993. Theory of Reflectance and Emittance Spectroscopy. Cambridge Univ. Press, Cambridge.

Hawke, B.R., Head, J.W., 1977. Impact melt on lunar crater rims in Impact and explosion cratering: Planetary and terrestrial implications; Proceedings of the Symposium on Planetary Cratering Mechanics, Flagstaff, Ariz., September 1317, 1976. New York, Pergamon Press, Inc., pp. 815-841.

Head, J.W., Murchie, S.L., Prockter, L.M., Robinson, M.S., Solomon, S.C., Strom, R.G., Chapman, C.R., Watters, T.R., McClintock, W.E., Blewett, D.T., Gillis-Davis, J.J., 2008. Volcanism on Mercury: evidence from the first MESSENGER flyby. Science 321, 69-72. http://dx.doi.org/10.1126/science.1159256.

Head, J.W., Murchie, S.L., Prockter, L.M., Solomon, S.C., Chapman, C.R., Strom, R.G., Watters, T.R., Blewett, D.T., Gillis-Davis, J.J., Fassett, C.I., Dickson, J.L., Morgan, G. A., Kerber, L., 2009a. Volcanism on Mercury: Evidence from the first MESSENGER flyby for extrusive and explosive activity and the volcanic origin of plains. Earth Planet Sci. Letters 285, 227-242. http://dx.doi.org/10.1016/j. epsl.2009.03.007. 
Head, J.W., Murchie, S.L., Prockter, L.M., Solomon, S.C., Chapman, C.R., Strom, R.G. Watters, T.R., Blewett, D.T., Gillis-Davis, J.J., Fassett, C.I., Dickson, J.L., Morgan, G. A., Kerber, L., 2009b. Evidence for intrusive activity on Mercury from the first MESSENGER flyby. Earth Planet. Sci. Lett. 285. http://dx.doi.org/10.1016/j epsl.2009.03.00.

Head, J.W., Chapman, C.R., Strom, R.G., Fassett, C.I., Denevi, B.W., Blewett, D.T., Ernst, C.M., Watters, T.R., Solomon, S.C., Murchie, S.L., Prockter, L.M., Chabot, N.L., Gillis-Davis, J.J., Whitten, J.L., Goudge, T.A., Baker, D.M.H., Hurwitz, D.M. Ostrach, L.R., Xiao, Z., Merline, W.J., Kerber, L., Dickson, J.L., Oberst, J., Byrne, P.K., Klimczak, C., Nittler, L.R., 2011. Flood volcanism in the northern high latitudes of Mercury revealed by MESSENGER. Science 30, 1853-1856. http://dx.doi.org/ 10.1126/science.1211997.

Helbert, J. et al. 2013. A comparison of the spectral properties of the Caloris and Rembrandt impact basins. In: Proceedings of the 44th Lunar Planetary Science Conference, p. 1496.

Holsapple, K.A., 1993. The scaling of impact processes in planetary sciences. Annu. Rev. Earth Planet Sci. 21, 333-373.

Izenberg, N.R., Klima, R.L., Murchie, S.L., Blewett, D.T., Holsclaw, G.M., McClintock, W.E., Malaret, E., Mauceri, C., Vilas, F., Sprague, A.L., Helbert, J., Domingue, D.L. Head III, J.W., Goudge, T.A., Solomon, S.C., Hibbitts, C.A., Darby Dyar, M., 2014. The low-iron, reduced surface of Mercury as seen in spectral reflectance by MESSENGER. Icarus 228, 364-374. http://dx.doi.org/10.1016/j. icarus.2013.10.023.

Johnson, J.R., Hoerz, F., 2003. Visible/near-infrared spectra of experimentally shocked plagioclase feldspars. J. Geophys. Res 108 (Issue E11), 5120. http://dx. doi.org/10.1029/2003JE002127.

Kerber, L., Head, J.W., Blewett, D.T., Solomon, S.C., Wilson, L., Murchie, S.L., Robinson, M.S., Denevi, B.W., Domingue, D.L., 2011. The global distribution of pyroclastic deposits on Mercury: the view from MESSENGER flybys 1-3. Planet. Space Sci. 59 (15), 1895-1909.

Kerber, L., Head, J.W., Solomon, S.C., Murchie, S.L., Blewett, D.T., Wilson, L., 2009. Explosive volcanic eruptions on Mercury: eruption conditions, magma volatile content, and implications for interior volatile abundances. Earth Planet. Sci. Lett. 285, 263-271. http://dx.doi.org/10.1016/j.epsl.2009.04.037.

Kiefer, W.S., Murray, B.C., 1987. The formation of Mercury's smooth plains. Icarus $72,477-491$

King, J.S., Scott, D.H., 1990. Geologic Map of the Beethoven (H-7) Quadrangle of Mercury, I-2048. USGS, Reston, VA.

Leake, M.A., 1982. The Intercrater Plains of Mercury and the Moon: tHeir Nature, Origin, and Role in Terrestrial Planet Evolution, Ph.D thesis. Univ. Arizona, Tucson, AZ.

Mancinelli, P., Minelli, F., Mondini, A. C., Pauselli, C., Costanzo, F., 2014. A downscaling approach for geological characterization of the Raditladi basin of Mercury. The Geological Society of London, Special Publication 401 SP401 Volcanism and Tectonism Across the Inner Solar System, doi: 10.1144/SP401.10.

Melosh, H.J., 1989. Impact Cratering: a Geologic Process. Oxford University Press, New York.

Murray, B.C., Belton, M.J.S., Danielson, G.E., Davies, M.E., Gault, D.E., Hapke, B O'Leary, B., Strom, R.G., Suomi, V., Trask, N., 1974. Mercury's surface: preliminary description and interpretation from Mariner 10 pictures. Science 185 http://dx.doi.org/10.1126/science.185.4146.169.
Osinski, G., Tornabene, L.L., Grieve, R.A.F., 2011. Impact ejecta emplacement on terrestrial planets. Earth Planet Sci. Lett. 310, 167-181.

Ostrach, L.R. et al. 2012. Distribution of impact melt on Mercury and the Moon. In: Proceedings of the 43rd Lunar Planetary Sci Conference, p. 1113.

Robinson, M.S., Murchie, S.L., Blewett, D.T., Domingue, D.L., Hawkins, S.E., Head, J. W. Holsclaw, G.M., McClintock, W.E., McCoy, T., McNutt, R.L., Prockter, L.M. Solomon, S.C., Watters, T.R., 2008. Reflectance and color variations on Mercury: Regolith processes and compositional heterogeneity. Science 321, 66-69.

Rava, B., Hapke, B., 1987. An analysis of the Mariner 10 color ratio map of Mercury. Icarus 71, 397-429. http://dx.doi.org/10.1016/0019-1035(87)90037-6.

Rothery, D.A., Thomas, R.J., Kerber, L., 2014. Prolonged eruptive history of a compound volcano on Mercury: volcanic and tectonic implications. Earth Planet. Sci. Lett. 385, 59-67.

Schaber, G.G., McCauley, J.F., 1980. Geologic map of the Tolstoj (H-8) Quadrangle of Mercury, I-1199. USGS, Reston, VA.

Schultz, P.H., 1977. Endogenic modification of impact craters on Mercury. Phys. Earth Planet. Inter. 15, 202-219.

Spudis, P.D., Prosser, J.G., 1984. Geologic map of the Michaelangelo (H-12) Quadrangle of Mercury, I-1659. USGS, Reston, VA.

Spudis, P.D., Guest, J.E., 1988. Stratigraphy and geologic history of Mercury. In: Vilas, F., Chapman, C.R., Matthews, M.S. (Eds.), Mercury. Univ. Ariz. Press, Tucson, pp. 336-373.

Strom, R.G., 1977. Origin and relative age of lunar and mercurian intercrater plains. Phys. Earth Planet 15, 156-172.

Thomas, R.J., Rothery, D.A., Conway, S.J., Anand, M., 2014. Mechanisms of explosive volcanism on Mercury: implications from its global distribution and morphology. J. Geophys. Res. Planets 119, 2239-2254. http://dx.doi.org/10.1002/ 2014JE004692.

Trask, N.J., Dzurisin, D., 1984. Geologic map of the Discovery (H-11) Quadrangle of Mercury. Map I-1658, Miscellaneous. Investigations Seres., U.S. Geological Survey, Denver, Colo.

Trask, N.J., Guest, J.E., 1975. Preliminary Geologic Terrain Map of Mercury. J. Geophys. Res. 80, 2461-2477. http://dx.doi.org/10.1029/JB080i017p02461.

Trask, N.J., 1976. Cratering history of the heavily cratered terrain on Mercury. Geol. Romana 15, 471-476.

Trask, N.J., Strom, R.G., 1976. Additional evidence of Mercurian volcanism. Icarus 28, 559-563.

Watters, W.A., Zuber, M.T., Hager, B.H., 2009. Thermal perturbations caused by large impacts and consequences for mantle convection. J. Geophys. Res. 114, E02001. http://dx.doi.org/10.1029/2007JE002964.

Weider, S.Z., Nittler, L.R., Starr, R.D., Crapster-Pregont, R.J., Peplowski, P.N., Denevi, B.W., Head, J.W., Byrne, P.K., Hauck II, S.A., Ebel, D.S., Solomon, S.C., 2015. Evidence for geochemical terranes on Mercury: Global mapping of major elements with MESSENGER's X-Ray Spectrometer. Earth Planet. Sci. Lett. 416, 109-120. http://dx.doi.org/10.1016/j.epsl.2015.01.023.

Whitten, J.L., Head, J.W., Denevi, B.W., Solomon, S.C., 2014. Intercrater plains on Mercury: Insights into unit definition, characterization, and origin from MESSENGER datasets. Icarus 241, 97-113. 